\title{
Oral Cancer Screening Techniques Utilized by West Virginia Dental Hygienists
}

\author{
Ashlee B. Charnoplosky \\ West Virginia University
}

Follow this and additional works at: https://researchrepository.wvu.edu/etd

\section{Recommended Citation}

Charnoplosky, Ashlee B., "Oral Cancer Screening Techniques Utilized by West Virginia Dental Hygienists" (2011). Graduate Theses, Dissertations, and Problem Reports. 3309.

https://researchrepository.wvu.edu/etd/3309

This Thesis is protected by copyright and/or related rights. It has been brought to you by the The Research Repository @ WVU with permission from the rights-holder(s). You are free to use this Thesis in any way that is permitted by the copyright and related rights legislation that applies to your use. For other uses you must obtain permission from the rights-holder(s) directly, unless additional rights are indicated by a Creative Commons license in the record and/ or on the work itself. This Thesis has been accepted for inclusion in WVU Graduate Theses, Dissertations, and Problem Reports collection by an authorized administrator of The Research Repository @ WVU. For more information, please contact researchrepository@mail.wvu.edu. 


\title{
Oral Cancer Screening Techniques Utilized by West Virginia Dental Hygienists
}

\author{
Ashlee B. Charnoplosky \\ Thesis submitted to the \\ School of Dentistry \\ at West Virginia University \\ in partial fulfillment of the requirements \\ for the degree of \\ Master of Science \\ in \\ Dental Hygiene
}

\begin{abstract}
Christina DeBiase, Ed.D., Chair
Susan Morgan, DDS

Cathryn Frere, M.S.Ed.

Department of Periodontics
\end{abstract}

Morgantown, West Virginia

2011

Keywords: oral cancer 


\section{ABSTRACT \\ Oral Cancer Screening Techniques Utilized \\ by West Virginia Dental Hygienists}

\section{Ashlee B. Charnoplosky}

Oral cancer has become a major public health problem. Health care professionals need to assume the responsibility of effectively screening all patients in their care for early signs of this disease. Too often, oral cancer is not diagnosed until it is in its later stages when treatment is not as effective. The late diagnosis contributes to the large number of deaths each year that could have been prevented had the patient had adequate screenings. Currently, there is no mandated law on providing oral cancer screenings

The purpose of this study is to examine the oral cancer screening protocols utilized by practicing dental hygienists in West Virginia. The results of this study will illustrate the need for a mandated oral cancer screening regimen. Surveys were sent to the homes of all practicing dental hygienists in West Virginia through two separate mailings. The survey addressed topics including health histories, frequency of updates, biopsies performed/referred, use of hand-held fluorescence detection devices, patient education; continuing education, and personal feelings of confidence on oral cancer related topics. The data obtained was analyzed for interpretation.

A response rate of $50.1 \%$ was achieved. The results showed that the majority of dental hygienists $(96 \%)$ are performing some form of oral cancer screenings on their patients. Dental hygienists varied on many aspects of their oral cancer screenings. The results of the survey reiterate the need for a universal oral cancer screening regimen to be utilized by all health care professionals. 


\section{DEDICATION}

This project is dedicated to my grandparents, Martha and Clifford Monk. You have provided me

with so many opportunities and support throughout the years. I will never be able to thank you enough for all you have done. 


\section{ACKNOWLEDGEMENTS}

Many individuals have provided their help in making my research possible. I would like to take this opportunity to thank them.

Dr. Christina DeBiase, thesis committee chair, for her support and guidance throughout not only this project, but my entire dental hygiene education.

Dr. Susan Morgan, thesis committee member, for her enthusiasm and expertise on the topic of my research.

Mrs. Cathryn Frere, thesis committee member, for her support and guidance through the aspects of scientific writing.

Mrs. Amy Funk, advisor, for all her help and support throughout the years of my dental hygiene education.

Ms. Lyndsey N. Gray, classmate and friend, for always having an encouraging smile and words of advice.

John Charnoplosky, for his love, support, and understanding throughout these busy years of graduate school.

Patricia and Michael Sowards, for always encouraging me to do my best. Thank you for standing behind me throughout all of my endeavors. I am so lucky to have you as parents.

Heather Sowards, sister and best friend, for always being the ear to listen and shoulder to lean on.

Drs. Diana O. Frum and Marcos Cid, for providing a work environment in which I have been able to grow as a hygienist and provide the best care possible for my patients. Thank you so much. 


\section{TABLE OF CONTENTS}

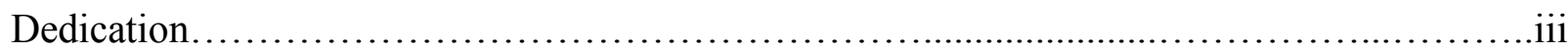

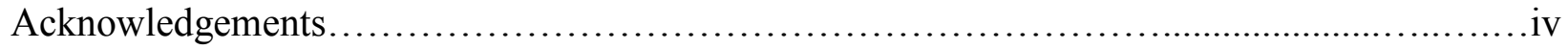

Table of Contents........................................................................

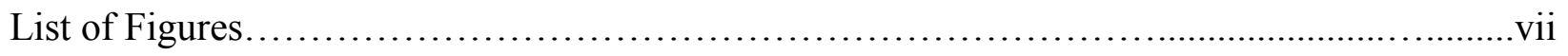

Chapter 1

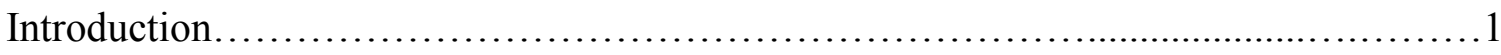

Statement of Problem................................................................

Purpose of Study.................................................................

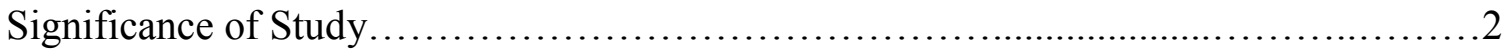

Questions to be Answered................................................................4

Operational Definitions........................................................4

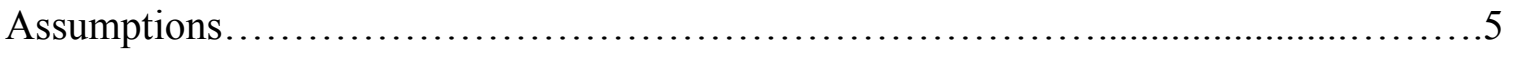

Limitations.......................................................................

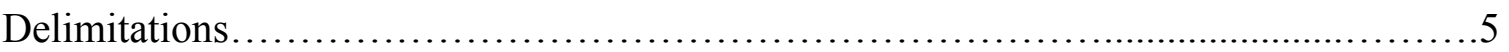

Chapter 2 Literature Review

Public Awareness.................................................................6

Types of Oral Malignancies.........................................................6

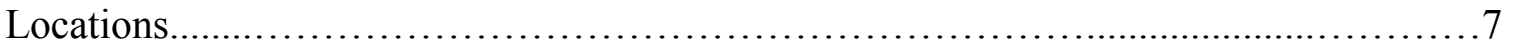

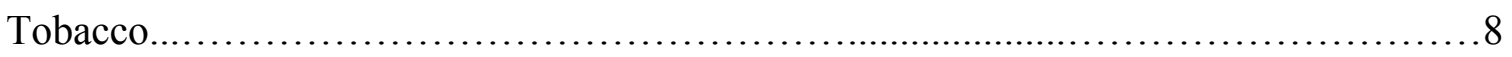

Alcohol................................................................................

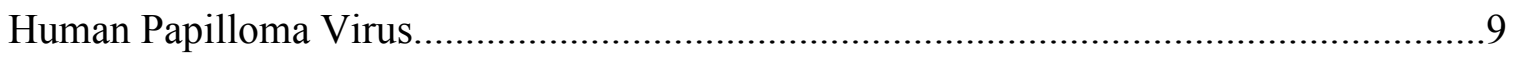

Screening Recommendations.................................................. 10 
Brush Biopsy............................................................ 11

Hand-Held Fluorescence Devices............................................... 12

Chapter 3

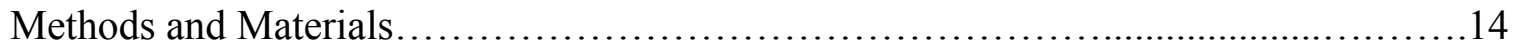

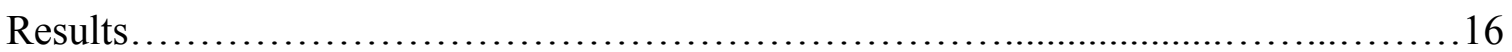

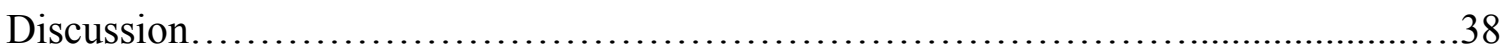

Conclusions................................................................. 43

Recommendations.......................................................... 44

Future Recommendations for Study...............................................46

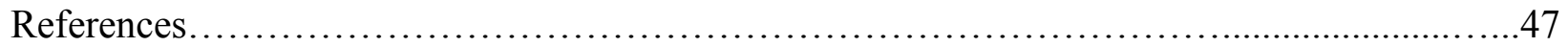

Appendices

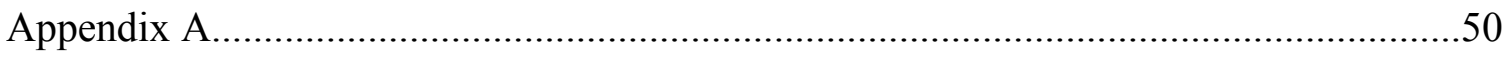

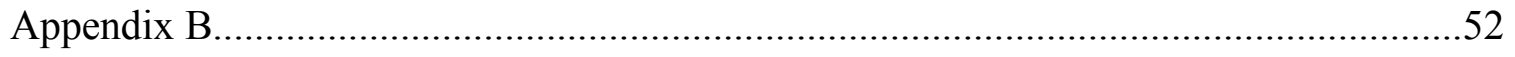

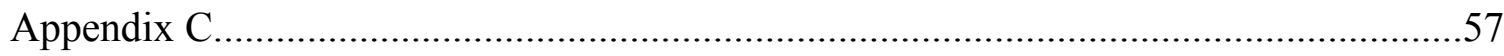

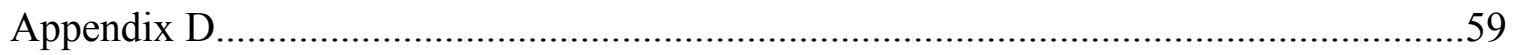

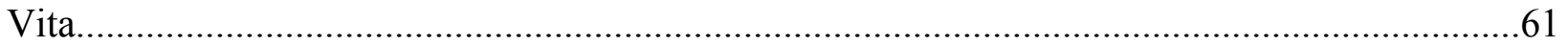




\section{List of Figures}

Figure 1 Dental Hygiene Degree Possessed by Respondents.......................................17

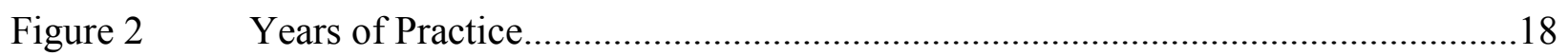

Figure $3 \quad$ Counties Represented by Respondents........................................................19

Figure 4 Oral Cancer Screenings Performed in Office....................................................22

Figure $5 \quad$ Who Performs the Oral Cancer Screening....................................................21

Figure $6 \quad$ Patient Informed During Oral Cancer Screening...........................................22

Figure $7 \quad$ Frequency of Performing Oral Cancer Screenings............................................23

Figure $8 \quad$ Age of Patients Who Receive Oral Cancer Screening......................................24

Figure 9 Instruct Patients to Perform Oral Cancer Screenings at Home...........................25

Figure $10 \quad$ Tobacco Cessation Materials Provided.............................................................26

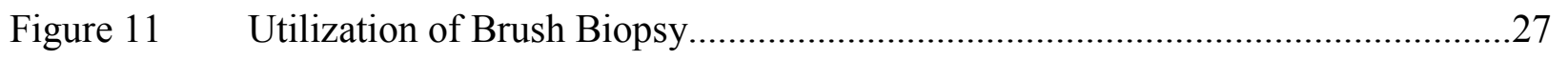

Figure 12-A Referral to Specialist for Biopsy..............................................................28

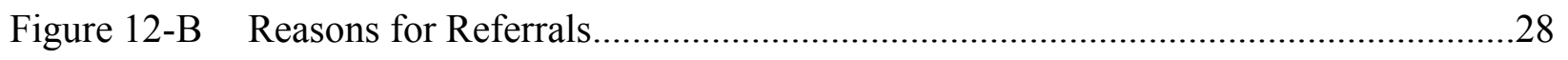

Figure 13 Annual Number of Biopsies Performed or Referred........................................29

Figure 14-A Dental Hygienists Using Fluorescent Screening Devices.................................30

Figure 14-B Hand-Held Fluorescence Screening Device Utilized...........................................30

Figure 15 Percentage of Hygienists Utilizing Intra-Oral Cameras for Patient Education.....31

Figure 16 Continuing Education Course Topics Completed................................................32

Figure 17 Frequency of New Health Histories Completed by Patients..............................33

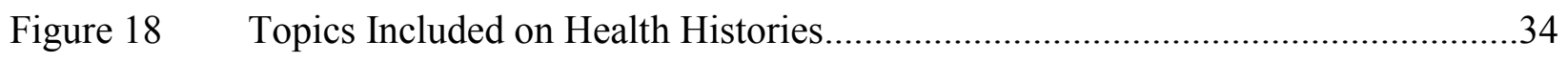

Figure 19 Confidence in Ability to Detect Ora Cancer.......................................................35

Figure $20 \quad$ Confidence in Knowledge of Oral Cancer........................................................35 
Figure 21 Confidence in Abiltity to Discuss Oral Cancer................................................36

Figure 22 Adequate Time Allotted to Complete Oral Cancer Screening.............................36

Figure 23 Hand-held Fluorescent Detection Devices Easy to Use......................................37

Figure 24 Confidence in Ability to Discuss Tobacco Cessation..........................................37 


\section{CHAPTER 1}

\section{INTRODUCTION}

Oral cancer continues to grow as a major health care problem for Americans.

Approximately 35,000 new cases of oral cancer are diagnosed each year, resulting in about 8,000

deaths annually. ${ }^{1,2}$ This statistic could be significantly decreased if dental professionals were performing adequate oral cancer screenings on every patient in their care. Only $20 \%$ of American dentists are performing oral cancer screenings that are considered adequate. ${ }^{1}$ The outcome of these unfortunate statistics is often late stage diagnosis which yields a much lower survival rate over a five year period. ${ }^{1,2,3}$ There is currently no mandated oral cancer screening regimen in place as there are for other cancers such as colon, breast, and prostate. Dental professionals need to be more aggressive in screening their patients for early signs of oral cancer. However, some of the responsibility must lie with patients themselves. Statistics show that only $60 \%$ of Americans see their dentist regularly each year. ${ }^{4}$ This low percentage can be attributed to many factors including access to care and cost of care. Patients must be educated about how to detect changes in their mouth and encouraged to seek professional care regularly or earlier if any problems arise.

\section{STATEMENT OF THE PROBLEM}

Dental hygienists, dentists, and other health professionals are not adequately performing oral cancer screenings on their patients due to a lack of knowledge, confidence, available technology, and/or time. The failure to perform this crucial exam is contributing to the high 
number of oral cancer diagnoses each year. Patients are not being educated on what lifestyle changes they can make to decrease their risk for developing oral cancer.

\section{PURPOSE OF THE STUDY}

The purpose of this study is to evaluate the oral cancer screening techniques used by dental hygienists currently practicing in West Virginia. The results of this study will strengthen the argument that an oral cancer screening protocol is needed by all dental professionals.

\section{SIGNIFICANCE OF THE STUDY}

Oral cancer is often a preventable disease that is directly related to lifestyle factors such as drinking alcohol, cigarette smoking, and poor nutrition. ${ }^{5}$ Patients who smoke and drink regularly are increasing their risk for developing oral cancer fifteen times. ${ }^{1,2}$ The five year survival rate for patients with localized oral cancer is approximately $80 \%$, whereas patients that exhibit distant metastases have only a $20 \%$ survival rate. Early detection and diagnosis can dramatically increase the survival rate. Unfortunately, two-thirds of patients that are diagnosed have already become symptomatic and about $50 \%$ of these individuals show evidence that the cancer has spread to regional lymph nodes. ${ }^{6}$ Patients that survive a first oral cancer are twenty times more likely to develop a secondary cancer. ${ }^{2}$

Age, gender, race, and socioeconomic factors also show some trends in oral cancer risk. In the past, oral cancer generally affected people over 40 years of age. Today, there is a 
noticeable increase in oral cancers of the tongue in patients under the age of forty. This may be directly related to an increase of the human papilloma virus from indiscriminate sexual practices. $^{2,7}$ Men are affected by oral cancer twice as often as women. ${ }^{1,2}$ African Americans are twice as likely to develop oral cancer as whites in the same age group. ${ }^{1,2}$ Some socioeconomic factors that can affect the development of oral cancer include income levels, education, access to health care, and a greater use of alcohol and tobacco products. ${ }^{2}$

The quality of life for oral cancer patients is greatly diminished due to changes caused by the disease and its treatment. Treatment can affect sense of taste and saliva production which can lead to an increase in dental caries. Depending on the size and location of the oral cancer, patients can experience severe pain chewing and swallowing. Speech can also be affected. Patients undergoing treatment for oral cancer are much more susceptible to dental infections and bone necrosis. $^{5}$

Survival rates for oral cancer have remained unchanged for the past three decades. ${ }^{3}$ Health care professionals need to take the time to adequately screen and educate all patients about oral cancer. 


\section{QUESTIONS TO BE ANSWERED}

1. Are oral cancer screenings being performed regularly in dental offices? Who is performing the screenings? How often are screenings performed? At what age are screenings performed?

2. Are patients notified that oral cancer screening has been performed? Are patients instructed to perform self screenings at home?

3. How often do patients complete a new health history? Does the health history used address topics related to oral cancer?

4. Are patients given tobacco cessation materials when appropriate?

5. Are intraoral cameras used for patient education and screening?

6. Are handheld fluorescence screening tools used? If so, what model?

7. Are brush biopsies performed when indicated? How many performed each year?

8. Are patients referred to a specialist for biopsy? What prompts referral?

9. What areas of the head/neck are included in oral cancer screening?

10. What are the personal feelings of dental hygienists on oral cancer screening, detection, knowledge, and discussion with patients?

\section{OPERATIONAL DEFINITIONS}

Mass Screening

Effective evaluation of all patients in your care for signs and risk factors of any disease, such as oral cancer. 


\section{ASSUMPTIONS}

1. All dental hygienists that responded to the survey are currently licensed and practicing in West Virginia.

2. All dental hygienists that responded to the survey completely understood each question.

3. There is a lack of adequate oral cancer screening among West Virginia dental hygienists.

\section{LIMITATIONS}

1. Survey response relative to extent of oral cancer screenings

2. Human error in interpreting survey responses

3. Opinions of respondents and inclusion of other information that was not solicited

4. No questions addressed nutritional counseling

5. Inadequate answers to survey questions regarding locations screened

\section{DELIMITATIONS}

Surveys were mailed to all currently practicing dental hygienists throughout the state of West Virginia. 


\section{CHAPTER 2}

\section{REVIEW OF LITERATURE}

\section{PUBLIC AWARENESS}

Oral cancer has become a major public health concern with over 270,000 new cases diagnosed annually worldwide. Treating oral cancers is also very costly both financially and emotionally. Due to late diagnosis, many oral cancers have a very low survival rate. One major contributor to the large number of oral cancer cases is the general public's lack of awareness of risk factors for oral cancer. ${ }^{5,8}$ Self-examination of the mouth is very simple and can be performed at home in front of a mirror. ${ }^{9}$ It is the professional responsibility of health care professionals to educate their patients in self-examination. Clinicians must review risk factors with their patients and teach them how to recognize any abnormalities in their mouth. ${ }^{4}$ Any sore or discoloration that is present for fourteen days or longer needs to be checked by a health care professional. $^{2,4}$ Patients should also report any of the following to their health care provider: lump or mass found in neck; problems with speaking, chewing, or swallowing; hoarseness; and numbness in the oral region.

\section{TYPES OF ORAL MALIGNANCIES}

Oral malignancies are classified into various types depending on the cells involved. The most common oral malignancies are squamous cell carcinomas. Other malignancies can be defined as oral malignant melanomas, mucoepidermoid carcinoma, or adenoid cystic 
carcinomas. $^{7}$ Approximately $90 \%$ of all oral malignancies are classified as squamous cell carcinomas. The most common areas for squamous cell carcinomas to develop are on the lower lip, lateral borders of the tongue, and the floor of the mouth. ${ }^{10}$ Oral malignant melanomas are less common, accounting for only about one percent of all oral cancers. These appear as a macular pigmentation, usually dark-brown to blue-black. Mucoepidermoid carcinomas contain three different cellular elements, squamous cells, mucus-secreting cells, and intermediate cells. Thirty-five percent of all salivary gland malignancies are mucoepidermoid carcinomas. These oral malignancies are painless, fixed, and slow-growing. Adenoid cystic carcinomas can affect both the major and the minor salivary glands. These are much less common than the other types of oral malignancies and appear as painless masses of the mouth or face. ${ }^{7}$

\section{LOCATION}

Although any part of the oral cavity can be affected by oral cancers, there are areas that are more commonly associated with malignancy. These areas include: lips, tongue, floor of mouth, palate, and tonsils. ${ }^{4}$ Approximately $40 \%$ of all oral cancers occur on the tongue. The lateral borders of the tongue are very susceptible to malignancy. Ingested carcinogens mix with one's saliva and collect in the floor of the mouth. This pool of fluids will constantly bathe the lateral borders of the tongue and the floor of the mouth exposing these areas to the carcinogens more than others. The lower vestibule is a common place to find a "snuff pouch". This is the name given to describe the corrugated tissue that results from the repeated action of holding smokeless tobacco in one place. The lower lip is also a common place for oral cancer due to its exposure to sunlight and carcinogens from holding a cigarette or pipe between the lips. 
Increased awareness of the damaging effects of sun exposure has helped to decrease the number of lip cancers. Oral cancers found in the posterior portion of the oral cavity are often larger and more advanced at time of diagnosis due to location. ${ }^{10}$

\section{TOBACCO}

Tobacco, in any form, is a major risk factor for oral cancer. Cigarettes, smokeless tobacco and pipes all contribute to the risk of oral cancer and other systemic cancers. Literature states that West Virginia ranks highest among the states in the use of smokeless tobacco. ${ }^{7}$ The increased use of smokeless tobacco has contributed to a decrease in lung cancer, but a measurable increase in oral cancers. ${ }^{2}$ Oral cancer patients, who continue to smoke after treatment, have a two to six times greater risk of developing a second malignancy of the upper aerodigestive tract. ${ }^{3}$ Upon cessation, former tobacco users experience an immediate rapid decline in their risk of developing oral cancer. ${ }^{11}$

Tobacco use not only increases one's risk for oral cancer, but can have damaging effects on the oral cavity. Tobacco users are at a greater risk for periodontal disease and chronic infections that can lead to heart disease. Smokeless tobacco users alter their normal oral epithelium in the location they keep the smokeless tobacco. This keratinization of the oral epithelium has been referred to as a "snuff pouch".

In many situations, tobacco users tend to pair their tobacco habit with alcohol consumption. ${ }^{12}$ Studies show that approximately three-fourths of all oral cancers in the United States are the result of the additive effect of tobacco and alcohol. ${ }^{11,12}$ 


\section{$\underline{\text { ALCOHOL }}$}

The repetitive intake of alcohol is the most important risk factor for oral cancer in nonsmokers. ${ }^{7}$ Alcohol is the best studied dietary factor linked to the development of oral cancer. ${ }^{13}$ Alcohol contains ethanol, nitrosamines, and polycyclic hydrocarbons which affect the oral mucosa resulting in dysplasia. ${ }^{11}$ Studies have shown that the alcohol present in wine is less harmful than that found in beer and liquor. ${ }^{11,14}$

As previously stated, alcohol and tobacco serve as independent factors for oral cancer. However, when combined, the additive risk factor for oral cancer increases thirty-five times for individuals that smoke two to four packs of cigarettes and consume more than four alcoholic beverages each day. ${ }^{11}$

\section{HUMAN PAPILLOMA VIRUS (HPV)}

Recent studies have shown a relationship between oral cancer and the human papilloma virus (HPV). One study found that fifty percent of oropharyngeal tumors contained the HPV genome. ${ }^{15}$ HPV-16 is associated with oral cancers, whereas HPV-18 is associated with cervical cancers. ${ }^{16}$ These HPV positive tumors are being discovered in younger patients, both male and female, who have no history of tobacco or alcohol use., ${ }^{2,17}$ In the years following the initial increase in HIV and AIDS cases, young individuals turned to other indiscriminate sexual practices believing they were much safer. ${ }^{18}$ The HPV infection is sexually transmitted, and one's risk has a direct relationship with number of sexual partners, young age at first intercourse, and history of genital warts. ${ }^{15-17}$ 
The majority of HPV related oral cancers are located on the lingual and palatine tonsils in the oropharynx. ${ }^{15,18}$ Oral cancer associated with HPV positive tumors has a better prognosis than oral cancer associated with other risk factors. ${ }^{15,18}$ In recent years, there has been a large debate over whether the HPV vaccine should be a mandated vaccine. Literature illustrates that both girls and boys can benefit from the protective aspects of the vaccine. ${ }^{16,18}$

\section{SCREENING RECOMMENDATIONS}

Too often, oral cancer goes undetected until the late stages. This is a result of the characteristic of oral cancers being subtle and asymptomatic during early onset. Treatment for late stage oral cancers is often complex, costly, and has poor outcomes. ${ }^{8}$ Screening guidelines exist for other types of cancers, including breast, cervical, and colorectal, but currently there is no mandated oral cancer screening regimen, only recommendations. Mass screening by trained professionals is the best approach to detecting oral cancer in its earliest stages. One study reports that only $14 \%$ of the US population can recall ever having an oral cancer screening. ${ }^{7}$ Most clinicians are not currently following the recommendations for oral cancer screenings set forth by the American Cancer Society. ${ }^{3}$ These guidelines include annual screenings of adults over 40 and screenings of those under 40 every three years. ${ }^{3}$ Data suggests that approximately 40,000 deaths worldwide could be prevented annually through routine oral cancer screenings. Oral cancer screening is a simple, non-invasive procedure that can be performed efficiently in about 5 minutes using only gauze, gloves, adequate lighting and loupes (optional). Most oral cancers are preceded by visible changes in the oral mucosa which can be detected early through adequate screening. 1,8 The visual portion of the exam should include the following areas: lips, buccal 
mucosa, hard and soft palate, tongue, oropharynx, nasopharynx, and larynx. Clinicians should palpate the lips, floor of mouth, and neck. ${ }^{1}$ The tip of the tongue should be grasped lightly with a piece of gauze allowing it to be pulled up and to the sides to adequately examine both sides and the floor of the mouth. ${ }^{3}$ Patients can easily be taught how to perform this simple, visual oral cancer screening at home. Patients need to be encouraged to notify their health care professional of any abnormal areas or sores that last longer than two weeks.

\section{BRUSH BIOPSY}

Exfoliative cytology, also referred to as a brush biopsy, can be a non-invasive way to diagnose early dysplasias and carcinomas. ${ }^{6}$ The brush biopsy was introduced to the dental profession in 1999 by the company OralScan Laboratories, Inc. ${ }^{6,19}$ The brush biopsy kit includes a special brush that is rotated over suspicious lesion to exfoliate cells from all three layers of the lesion: basal, intermediate, and superficial. ${ }^{6,19}$ The procedure is virtually painless and does not require any topical or local anesthesia. ${ }^{19}$ Once the sample has been obtained, the cell material is transferred to a provided slide to be sent to the OralCDx laboratory for analysis. ${ }^{19}$

The effectiveness of the brush biopsy is dependent on the dental professional's engagement in actively screening patients for oral cancer. ${ }^{6}$ A positive result from the brush biopsy would illicit the need for a conventional excisional biopsy. ${ }^{6}$ Research shows that the sensitivity of the brush biopsy ranges from $71.4 \%$ to $100 \%$ and the specificity from $32 \%$ to $100 \%$. A low percentage of false negatives have been reported. ${ }^{19}$ 


\section{HAND-HELD FLUORESCENCE DEVICES}

The introduction of hand-held fluorescent devices to screen for oral cancer has allowed the practitioner to quickly screen a patient for suspicious tissues or lesions otherwise not seen with the "naked eye". Earlier detection and diagnosis leads to improved outcomes. These devices are used as a "discovery tool" and do not diagnose oral cancer. ${ }^{20}$ Four commonly used devices include: ViziLite Plus ${ }^{\circledR}$ with T-Blue; VELscope ${ }^{\circledR}$; Orascoptic DK $®$; and Identafi 3000 Ultra ${ }^{\circledR}$. Each device works differently to assist the practitioner in detecting suspicious tissues or lesions.

ViziLite Plus ${ }^{\circledR}$ with T-Blue was first introduced in 2002. It improves visualization of lesions through the use of a chemiluminescent light. The patient first rinses with a solution of acetic acid for at least thirty seconds and then a "wand-like" instrument is moved around the mouth. Through the use of special eyewear, any abnormal tissue areas will appear white. The practitioner is then able to use a phenothiazine dye also referred to as T-Blue "oral lesion marking system" to illustrate the exact area to be biopsied. ${ }^{1,20}$ The use of the T-Blue stain allows the lesion to be visible in normal lighting. This system of screening patients for suspicious lesions is cost effective and does not require much time. The materials are packaged in a single use disposable system. This method of screening is recommended once a year for all patients over the age of eighteen. ${ }^{20}$

Another hand-held screening tool is the Visually Enhanced Lesion scope, or the VELscope ${ }^{\circledR}$, introduced in $2006 .{ }^{19}$ This tool emits a blue light that excites the normal tissue causing it to appear a shade of fluorescent green. Abnormal tissue loses the ability to emit 
fluorescence making it appear darker which in turn allows it to be differentiated from normal tissue. $^{1,19,20}$ One advantage of using the VELscope ${ }^{\circledR}$ is that the patient does not have to rinse with any stain or dye. An intraoral camera is attached to the device to allow for photography of lesions. Using the VELscope ${ }^{\circledR}$ takes less than three minutes. ${ }^{20}$

In 2008 the Orascoptic $\mathrm{DK}{ }^{\circledR}$ was release. It is a diagnostic kit that not only visualizes oral lesions on soft tissue, but can also show fractured teeth and early carious lesions. This device uses a battery powered LED light to transilluminate the teeth to show fractures and carious lesions. To visualize the oral lesions on soft tissue, the patient must first rinse with an acetic acid solution to agitate the cells. Then the LED light is changed to a fluorescent source and any suspicious lesions appear white. ${ }^{1,20}$ The Orascoptic DK $®$ is completely autoclavable and takes less than five minutes to complete. ${ }^{20}$

One of the most recent additions to the family of hand-held oral cancer detection devices is the Identafi 3000 Ultra ${ }^{\circledR}$, introduced in 2009 . This device uses a series of three different wavelengths of light to complete the screening. A white LED light is used first to illuminate the oral cavity and enhance visualization. A second wavelength, violet light, excites that normal tissue causing it to appear fluorescent and abnormal tissue remains dull. Special eyewear is used to enhance this step. The final wavelength of light used is a green-amber light which differentiates between normal and abnormal tissue vasculature. ${ }^{1}$ 


\section{CHAPTER 3}

\section{METHODS AND MATERIALS}

Prior to mailing a survey to all practicing dental hygienists in the state of West Virginia, an application to the Institutional Review Board of West Virginia University was completed online. The application was accepted for exempt status by the review board. A copy of the exemption can be found in Appendix A. A copy of the survey and cover letter can be found in Appendix B.

A list of practicing dental hygienists in West Virginia was obtained from the state dental board ( $\mathrm{n}=863)$. This list was current as of March 2011. A 27 item survey was sent to the home address of each dental hygienist. Enclosed in the envelope was a cover letter explaining that the purpose of this survey was to evaluate what oral cancer screening techniques and tools are currently being used by dental hygienists practicing in West Virginia. It was also explained in the cover letter that the survey was a partial fulfillment of a master's degree in dental hygiene. The cover letter stated that participation in the survey was completely voluntary and would take no more than ten minutes to complete. The prospective participants were also informed that their responses would be kept as confidential as possible. A self-addressed, stamped envelope was also included for participants to return their completed survey.

Two mailings were utilized to strengthen the response rate. The first mailing was sent out on April 1, 2011 with a requested return date of May 1, 2011. The second mailing was sent out on May 2, 2011 with a requested return date of June 1, 2011. 
The survey began with instructions to circle the best answer and explain thoroughly when necessary. The survey included 26 multiple choice questions and one open ended question. The 26 multiple choice questions included eight yes or no; four check all that apply; and 14 questions with three or more answer choices. Participants that answered that their office was not currently performing oral cancer screenings on patients were asked to skip to question nine. Information gathered from the survey included:

- Dental hygiene degree obtained and number of years practicing

- Name of West Virginia county where practicing

- Oral cancer screening regimen in current office (how often and performed by whom)

- Patient notified during oral cancer screening

- Age to begin in-office oral cancer screenings

- Instructions to complete oral cancer screening at home

- Tobacco cessation (materials provided for patients to take home)

- Brush biopsy performed at office

- Referral to specialist for biopsy and reasons behind referral

- Use of hand-held fluorescence oral cancer screening tool (name model used)

- Intra-oral camera use for patient education

- Health history updates and topics addressed 
- Continuing education guidelines and courses selected

- Locations screened for oral cancer

- Personal feelings on oral cancer detection, knowledge, conversation with patient, etc.

Data obtained from survey responses was entered into an Excel spreadsheet. The data was then analyzed for interpretation.

\section{RESULTS}

A response rate of $50.1 \%(\mathrm{n}=432)$ was obtained from the returned surveys of both mailings. The following graphs represent the answers from each survey question. 
Respondents were almost equally divided between having a bachelor's degree and an associate's degree (46\% and 52\%, respectively). A small number of respondents, $2 \%$, stated that they had obtained a degree other than what was listed. Of the ten respondents that chose "Other" for their degree classification, eight had obtained a master's of science in dental hygiene, one had the Canadian equivalent of a dental hygiene degree, and one stated that they had obtained a certificate of dental hygiene. See Figure 1.

Figure 1: Dental Hygiene Degree Possessed by Respondents $(n=432)$

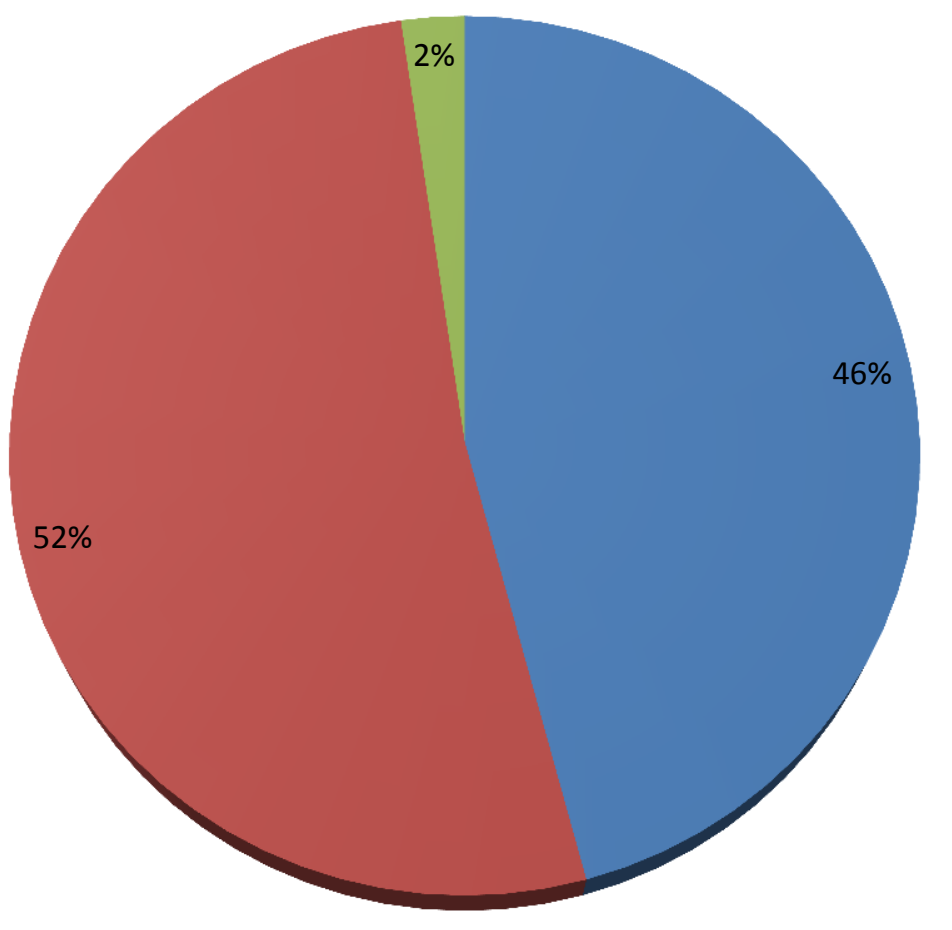

Bachelors

- Associate

Other 
The majority of respondents have been practicing dental hygiene for more than twentyone years $(39 \%)$. The second largest group of respondents had been practicing for less than five years $(23 \%)$. The rest of the respondents were more evenly dispersed through their years of practice. See Figure 2.

Figure 2: Years of Practice $(n=429)$

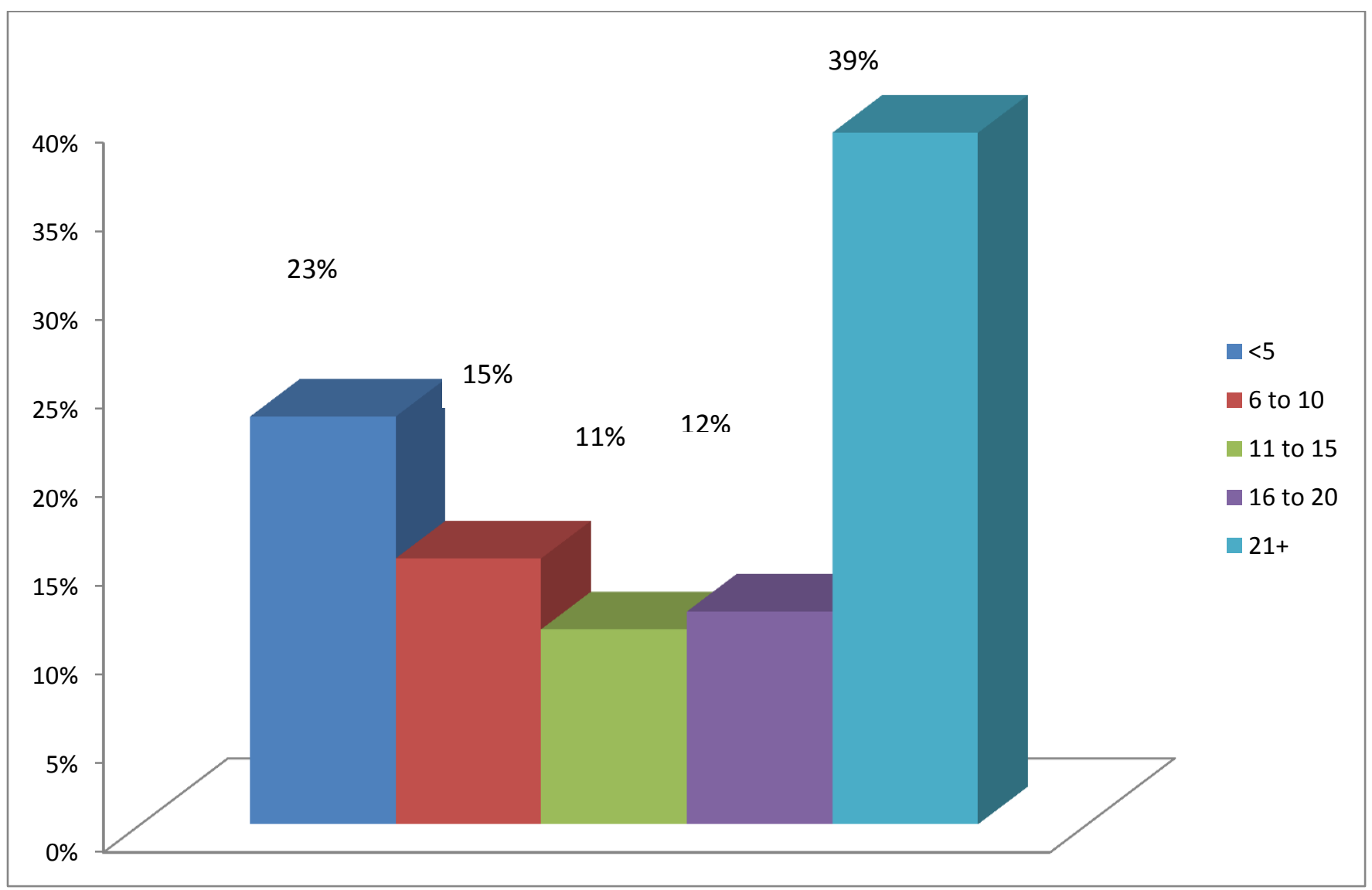


Of the fifty-five counties in West Viginia, forty-eight were represented by respondents.

Some hygienists are currently practicing in more than one county. See Figure 3.

\section{$\underline{\text { Legend }}$}

\begin{tabular}{|c|c|}
\hline No Respondents & 31-40 Respondents \\
\hline 1-10 Respondents & 41-50 Respondents \\
\hline 11-20 Respondents & 51-60 Respondents \\
\hline 21-30 Respondents & $61+$ Respondents \\
\hline
\end{tabular}

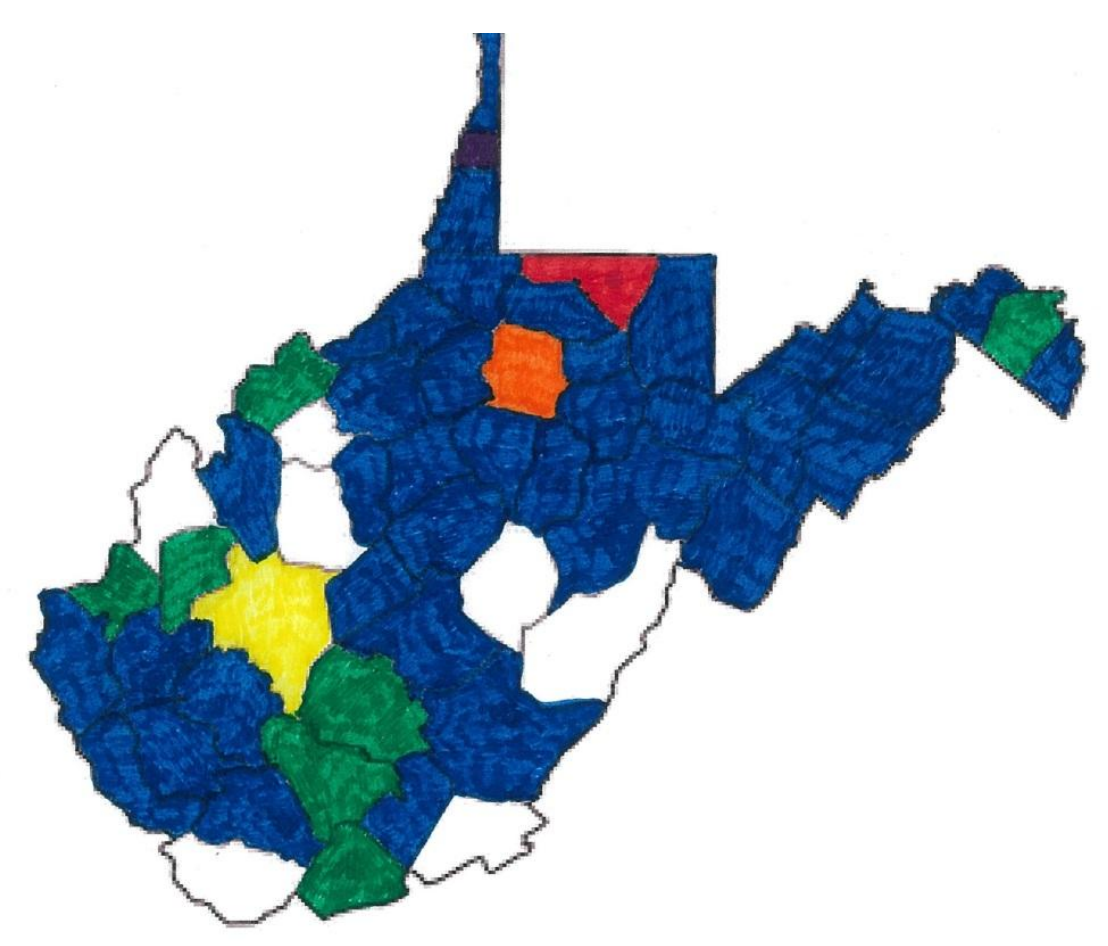


The majority of dental hygienists report that their current office performs oral cancer screenings on patients (96\%). Four percent of the respondents stated that their office did not perform oral cancer screenings on patients. Reasons that were given for this lack of screening include working in an orthodontic or pediatric office and being employed as a public health hygienist. See Figure 4.

Figure 4: Oral Cancer Screenings Performed in Office $(n=425)$

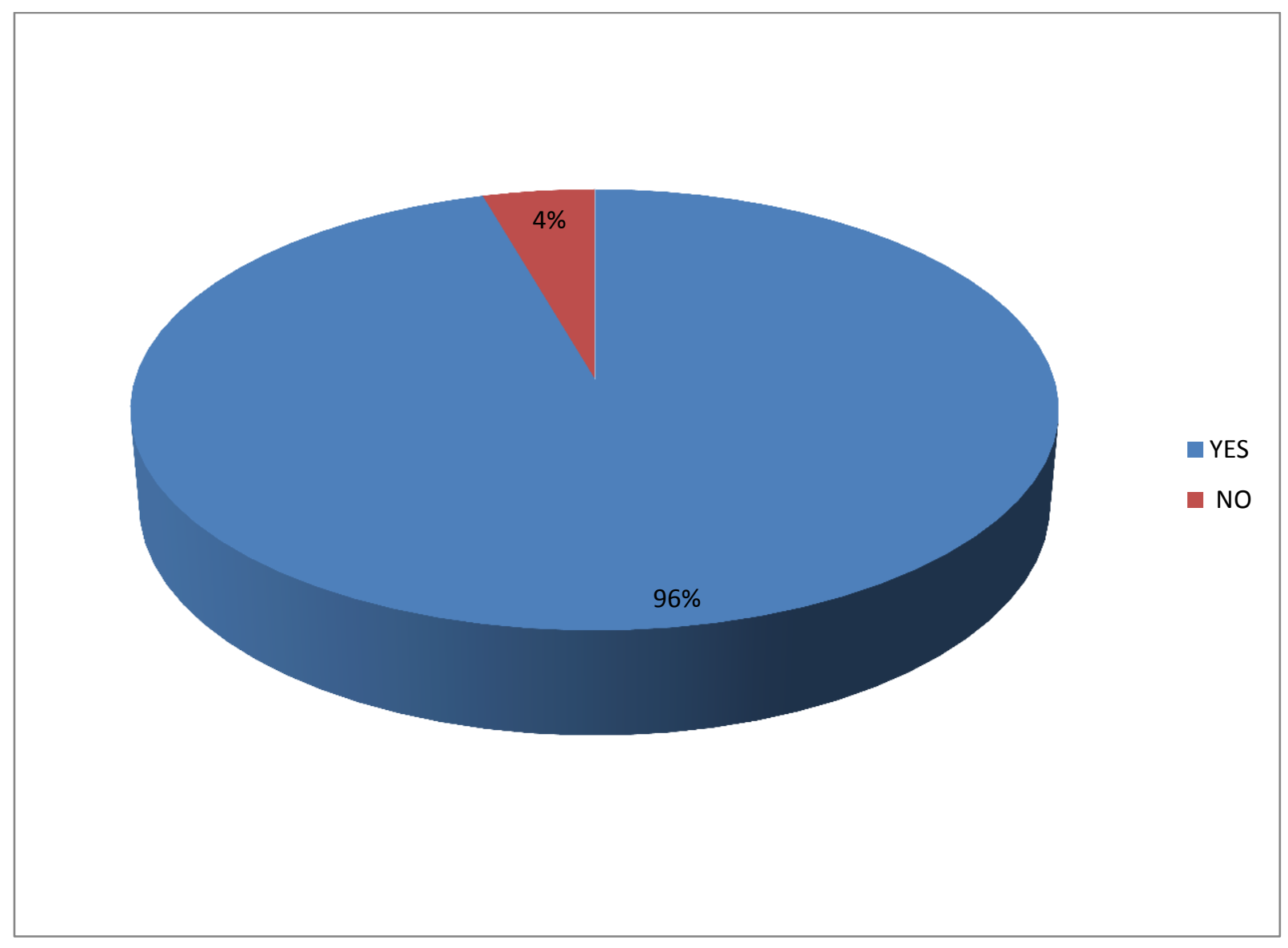


Both dental hygienists and dentists have been trained to adequately perform an oral cancer screening. The majority of the respondents stated that both professionals perform the oral cancer screenings in their office $(75 \%)$. In some offices, the oral cancer screening is performed by either the hygienist (14\%) or the dentist 11\%). See Figure 5.

Figure 5: Who Performs the Oral Cancer Screening $(n=406)$

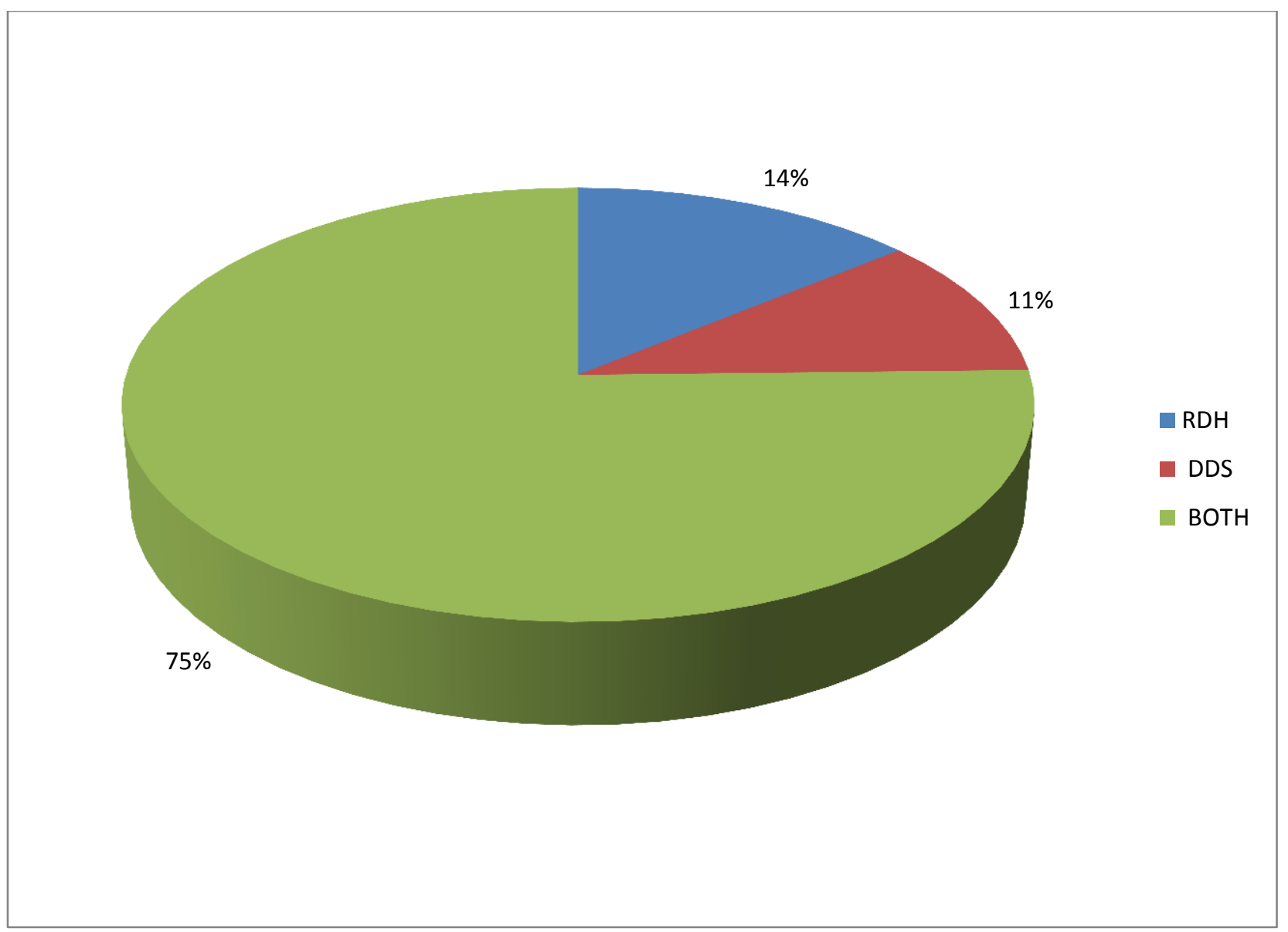


Many patients are not aware when an oral cancer screening is being performed. This lack of awareness leads many patients to falsely believing that no oral cancer screening was performed. Only $73 \%$ of respondents state that they inform their patients when doing an oral cancer screening. See Figure 6.

Figure 6: Patient Informed During Oral Cancer Screening $(n=392)$

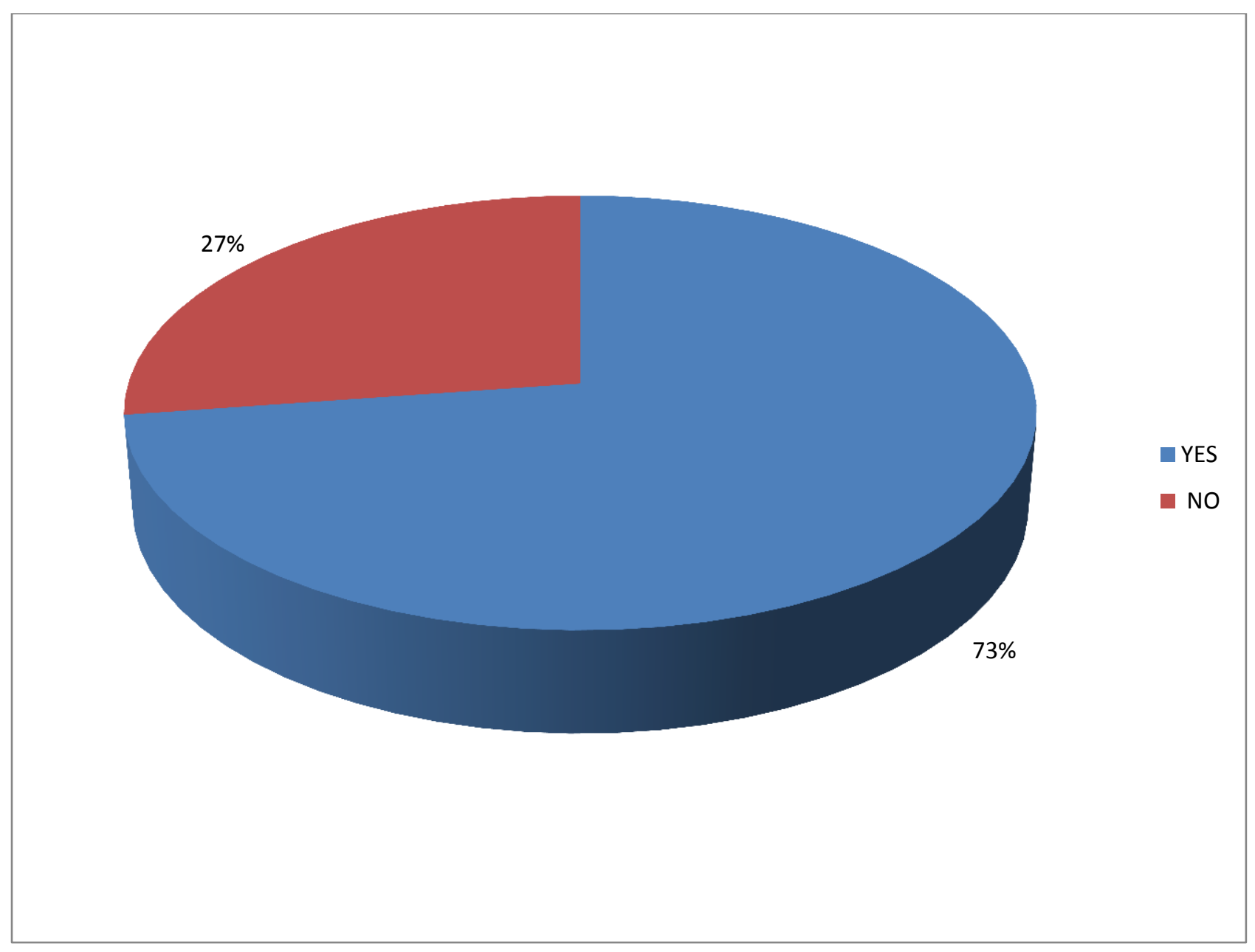


The majority of respondents state that an oral cancer screening is performed at every recall appointment (95\%). A small number of respondents state that the screening is only performed at the first appointment or when a problem is present. See Figure 7.

Figure 7: Frequency of Performing Oral Cancer Screenings ( $n=380)$

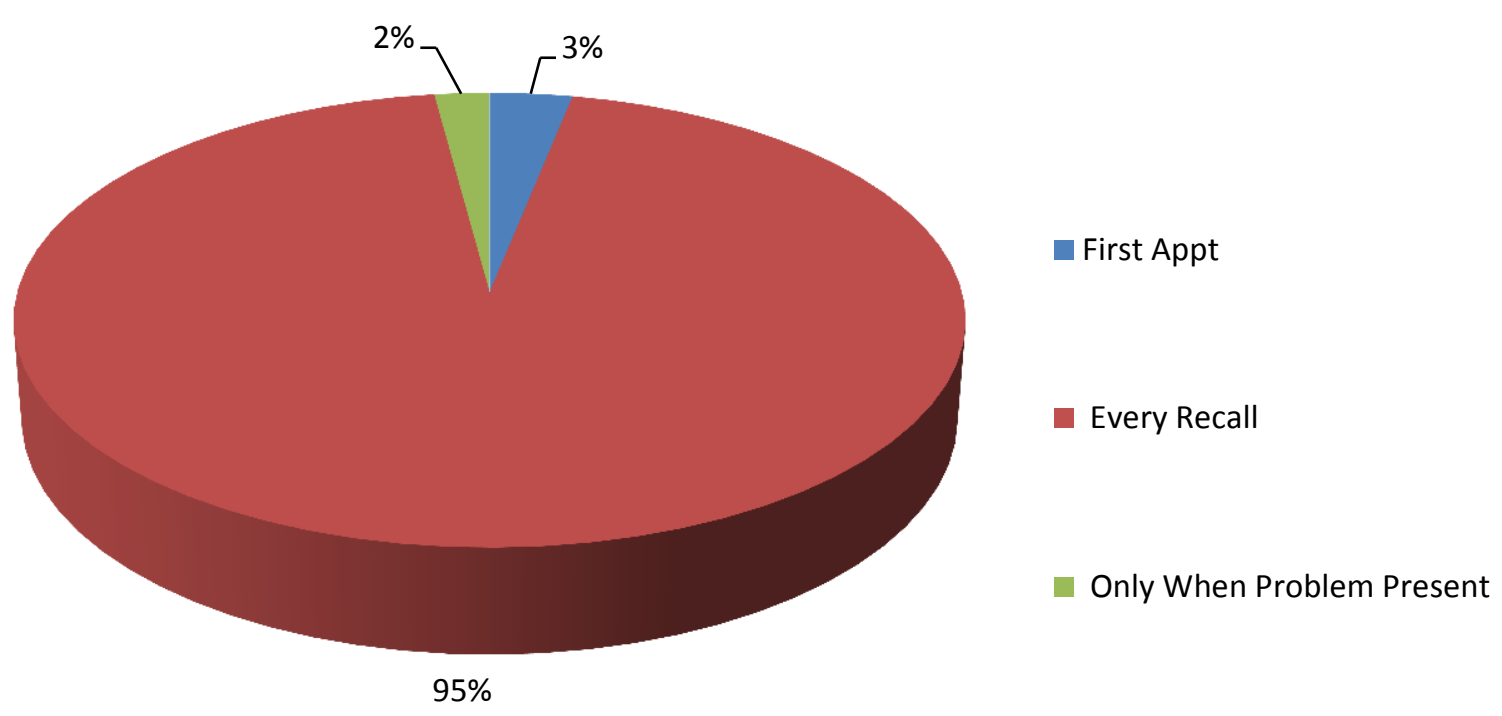


There was a significant variance in what age dental hygienists begin performing oral cancer screenings. The majority (32.4\%) state that they perform an oral cancer screening on every patient, regardless of age. The next highest age range to receive regular oral cancer screenings is sixteen to twenty years old (28.4). See Figure 8.

Figure 8: Age of Patients Who Receive Oral Cancer Screening ( $n=401)$

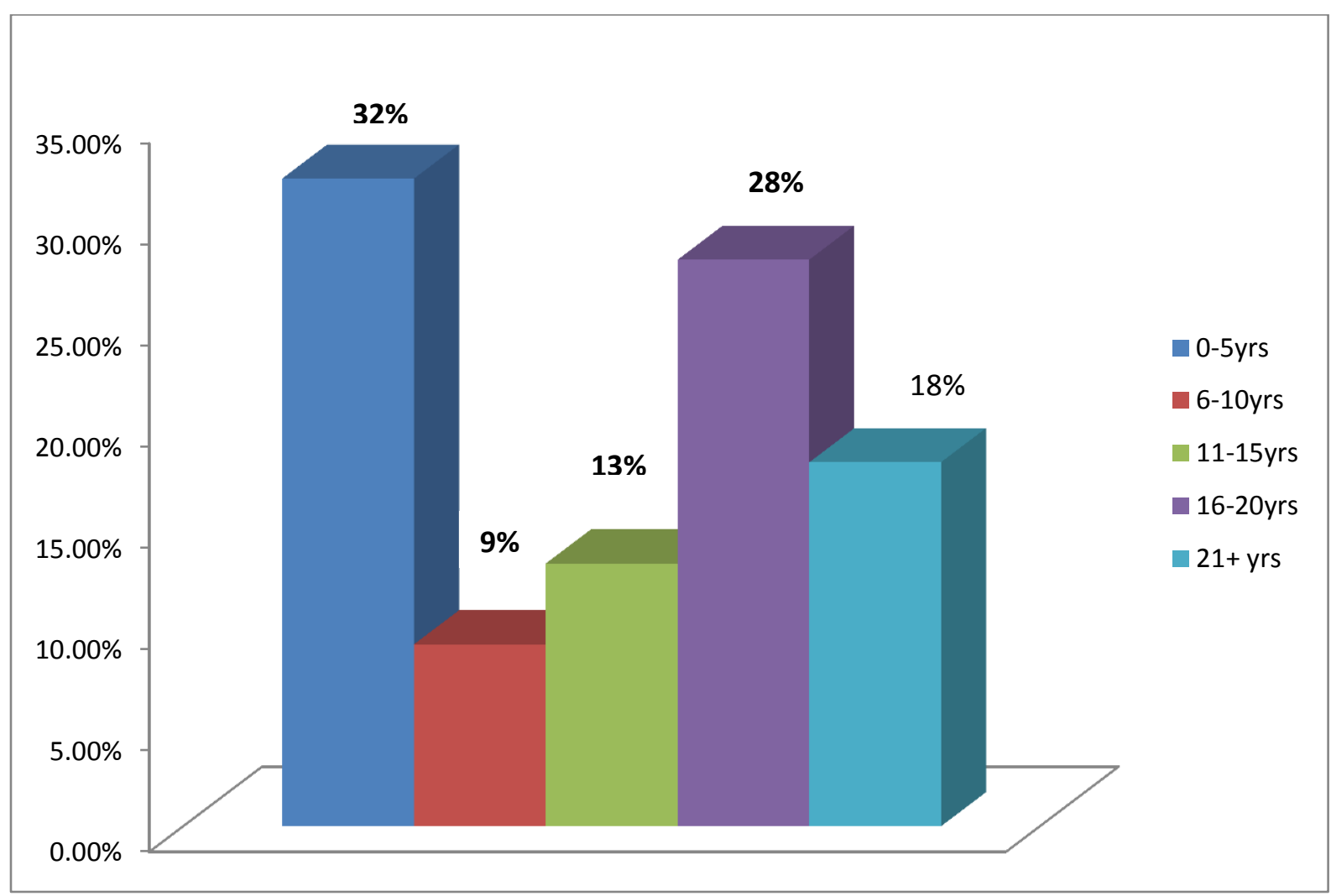


Patient education is an integral part of the fight to decrease the oral cancer rate. Patients need to be educated by dental professionals on what to look for when performing a selfexamination. The respondents were almost equally divided on whether they instruct patients to perform oral cancer screenings at home or not. See Figure 9.

Figure 9: Instruct Patients to Perform Oral Cancer Screenings at Home ( $n=419)$

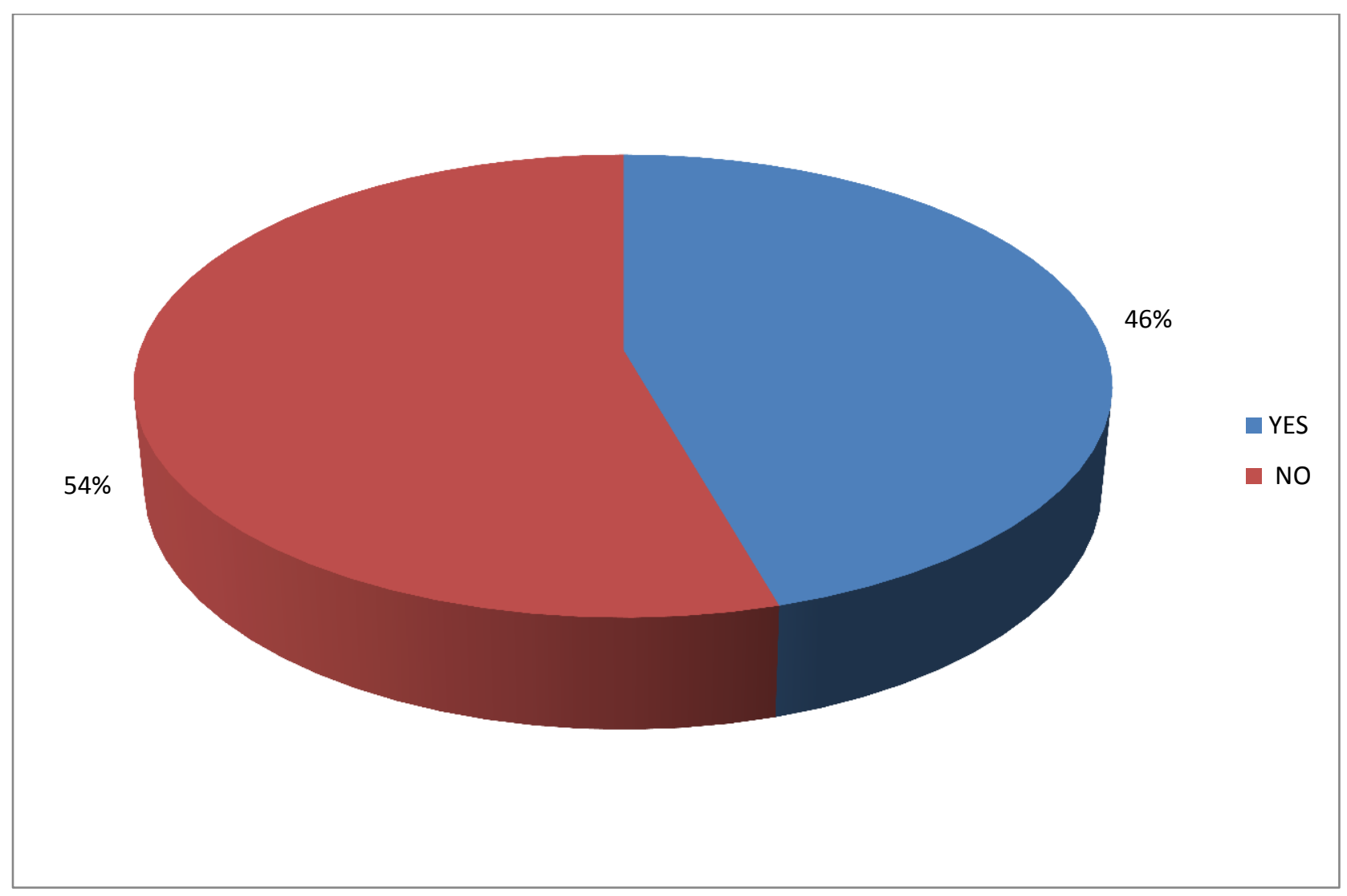


West Virginia has multiple tobacco cessation tools that can be obtained by the dental hygienist and given to patients who are interested in quitting. The majority (89\%) of respondents are providing some type of tobacco cessation counseling and/or materials to their patients. See Figure 10.

Figure 10: Tobacco Cessation Materials Provided $(n=423)$

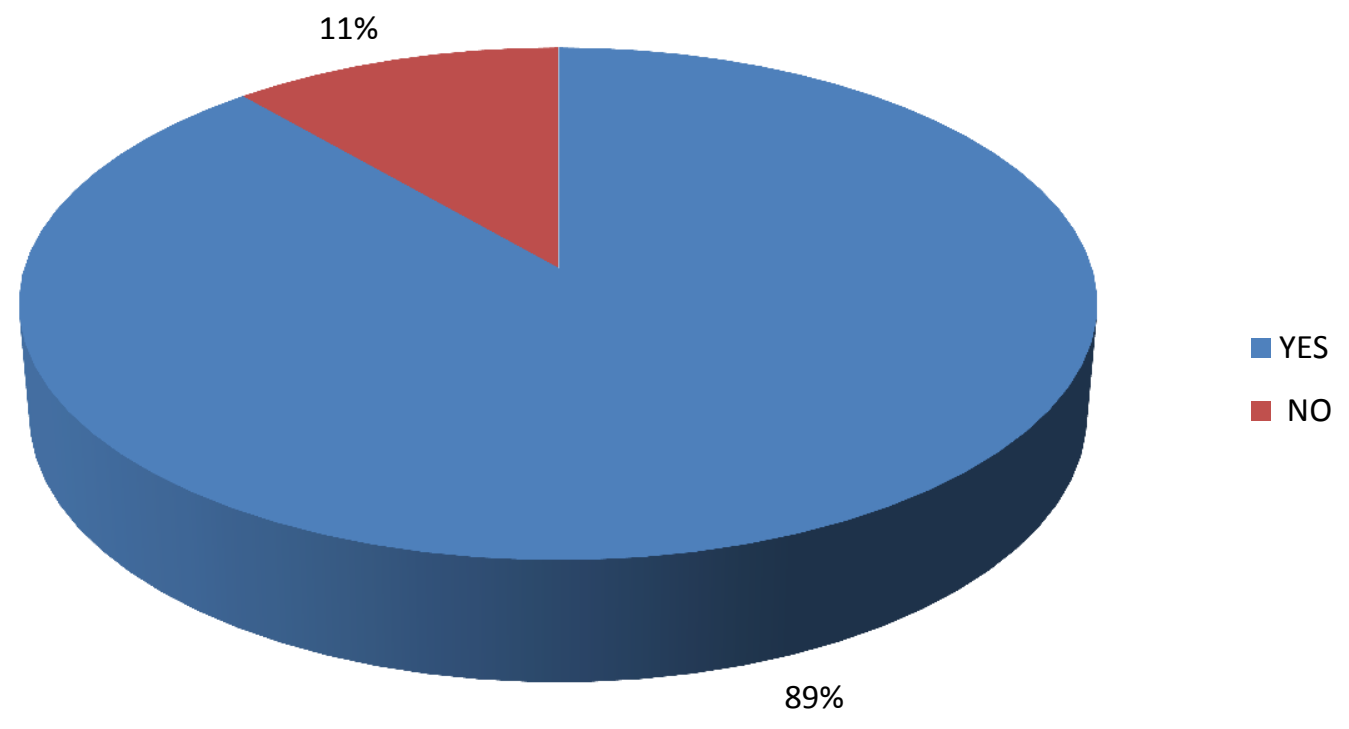


The oral brush biopsy is a quick, easy, and inexpensive way to check suspicious tissue for the presence of any abnormal cells. Unfortunately, only $26 \%$ of the respondents claim that the oral brush biopsy is being used in their office. See Figure 11.

Figure 11: Utilization of Brush Biopsy ( $n=423)$

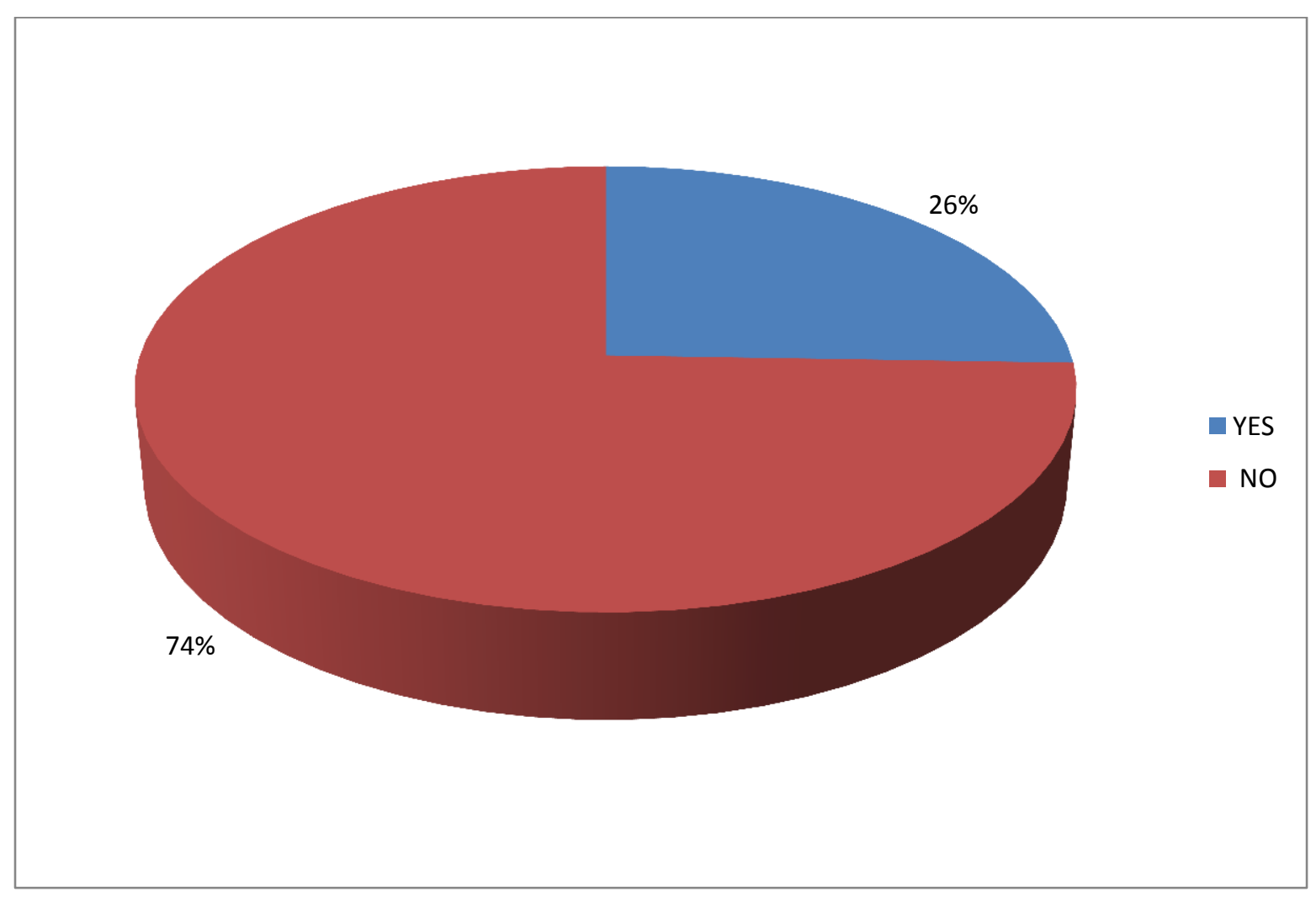


Almost all (97\%) of the respondents stated that their office refers patients to a specialist for biopsy of a suspicious lesion. (See Figure 12-A). The reasons that prompt these referrals can be found in Figure 12-B. Respondents that selected the "other" choice further explained their reasons for biopsy. These reasons included pain, location, and overall appearance.

Figure 12-A: Referral to Specialist for Biopsy $(n=423)$

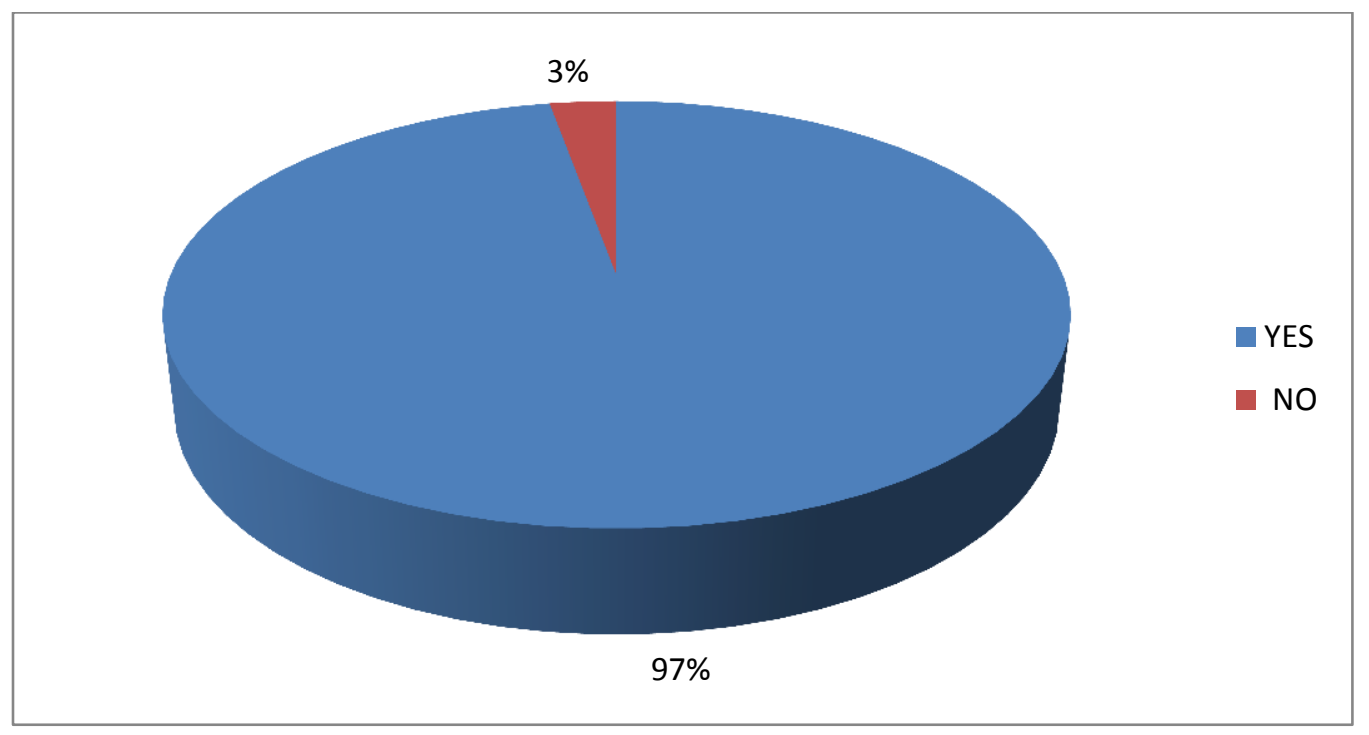

Figure 12-B: Reasons for Referrals $(n=423)$

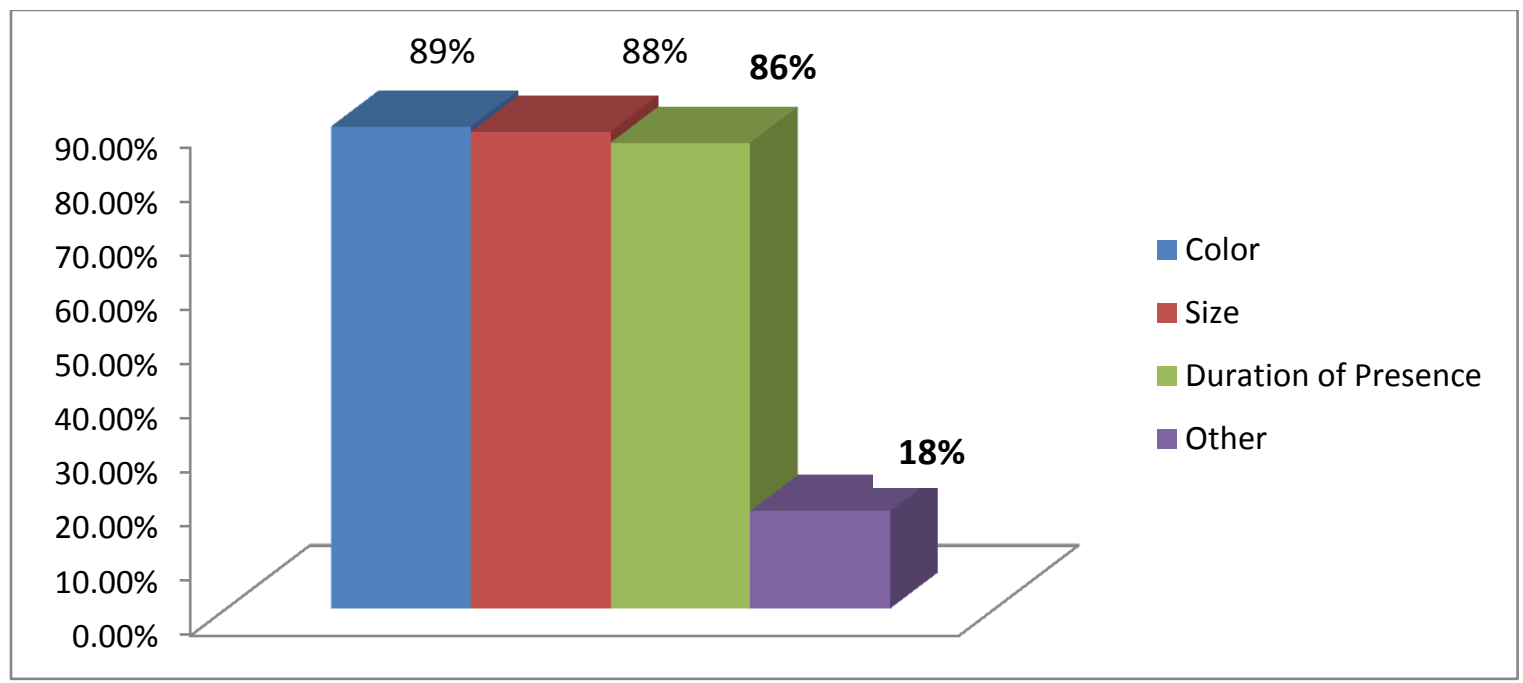


The majority of respondents (74\%) stated that their current office of employment refers ten or fewer patients each year for biopsy of suspicious tissue. This also includes performing a brush biopsy within the office. See Figure 13.

Figure 13: Annual Number of Biopsies Performed or Referred (n=407)

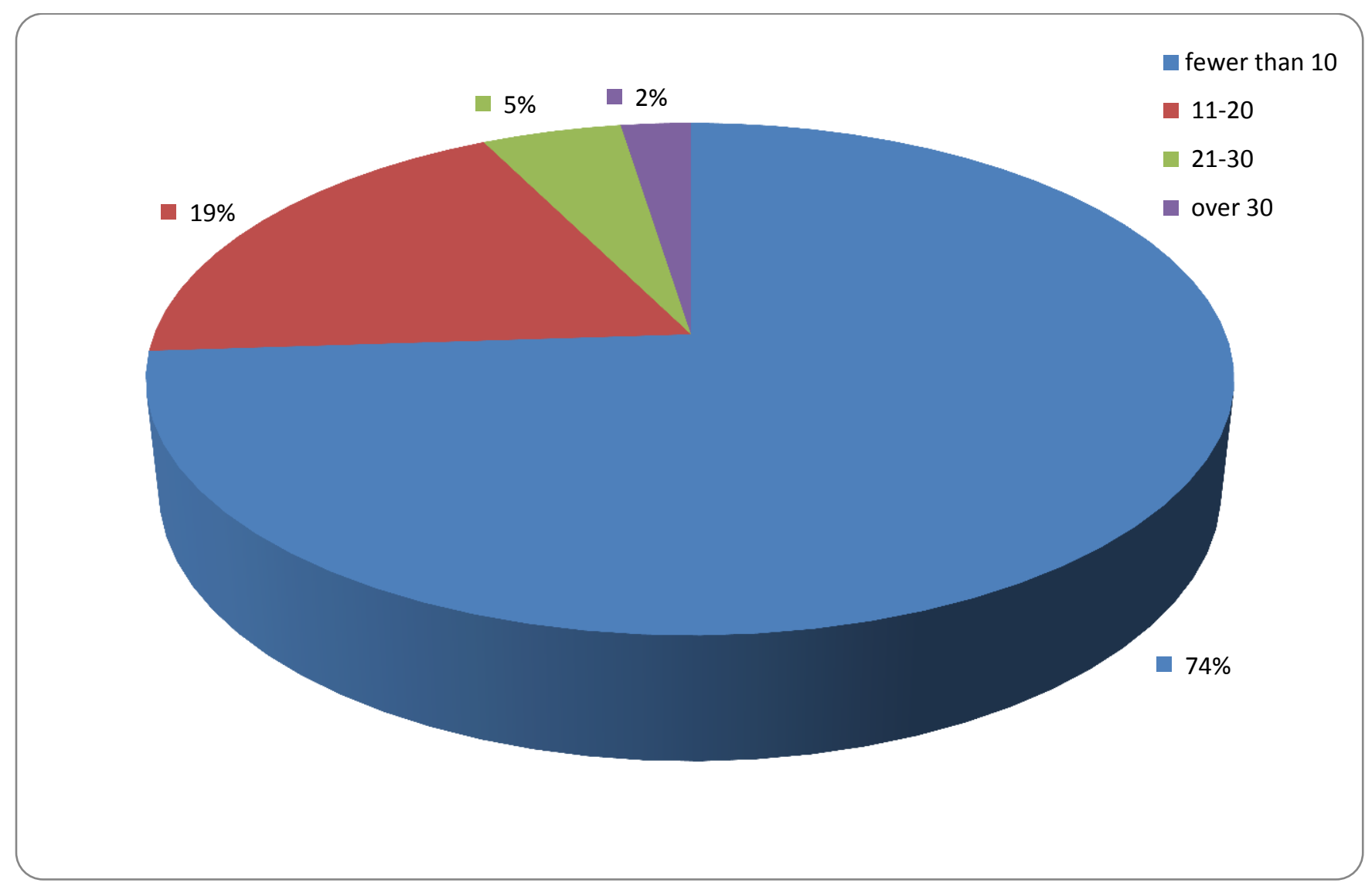


The majority of respondents (84\%) stated they do not currently use a hand-held fluorescence tool to aid in oral cancer detection. See Figure 14-A. Respondents who replied "Yes" to this question were asked to identify which hand-held fluorescence tool they were using. The majority of dental hygienists that use the hand held fluorescence devices are using the VELScope ${ }^{\circledR}$ system. Many hygienists did not specify the device being used. See Figure 14-B

Figure 14-A: Dental Hygienists Using Fluorescent Screening Devices $(n=421)$

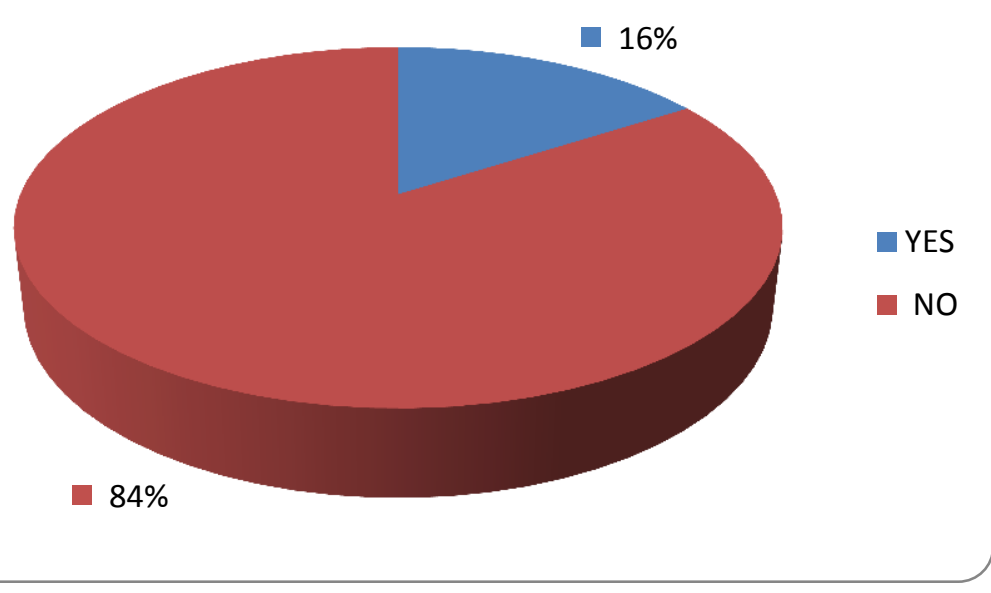

Figure 14-B: Hand-Held Fluorescence Screening Device Utilized (n=69)

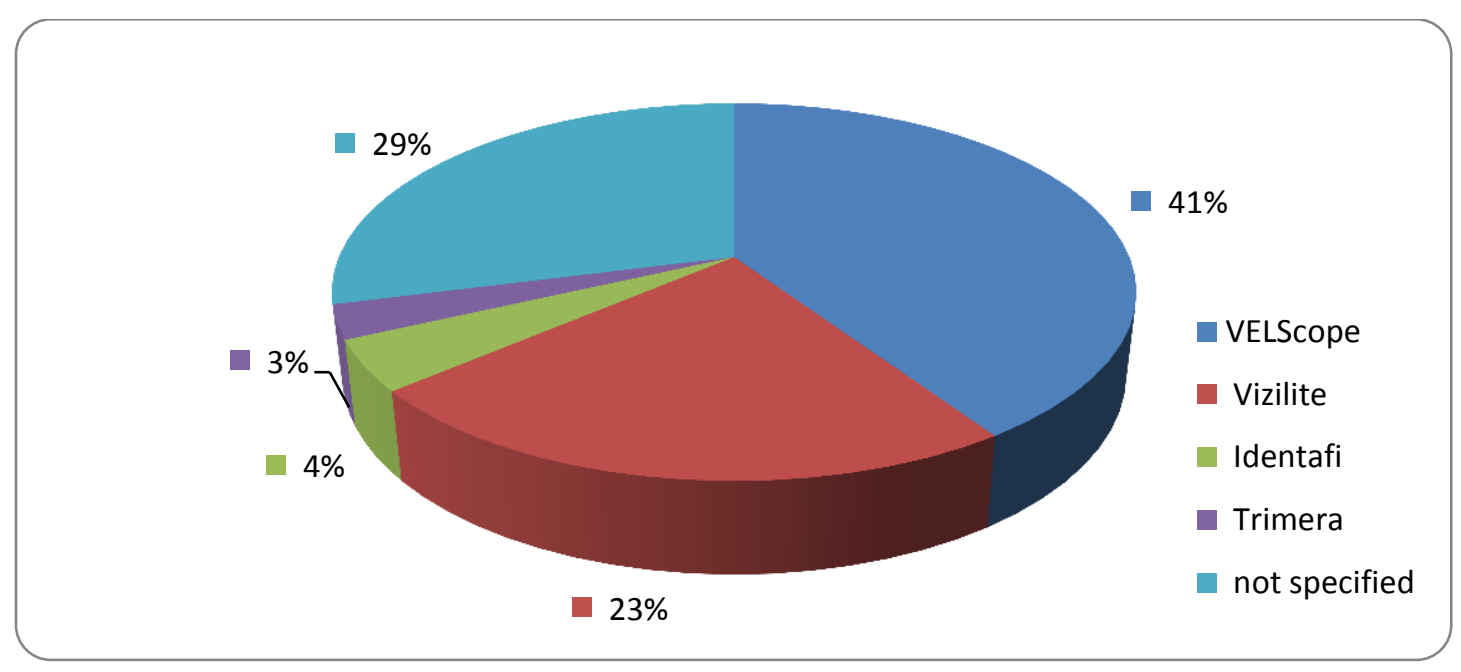


Intra-oral cameras are an excellent adjunct tool for patient education. They provide the patient with a close-up image of what they may not be able to see with the naked eye. Only slightly more than half of the respondents state that they are using these tools for patient education. See Figure 15.

Figure 15: Percentage of Hygienists Utilizing Intra-Oral Cameras for Patient

\section{Education $(n=423)$}

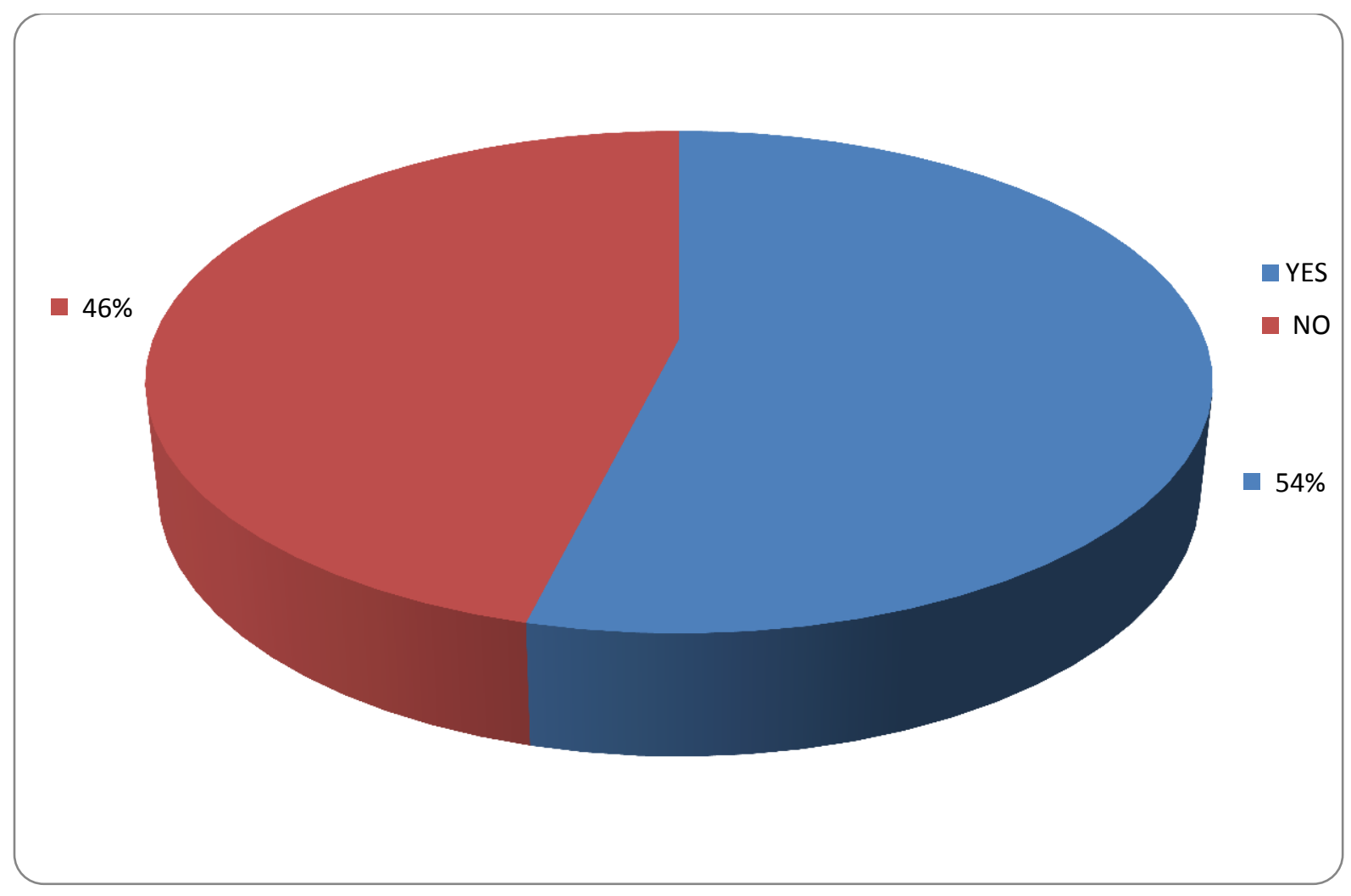


Registered dental hygienists in West Virginia are required to complete twenty hours of continuing education courses every two years to keep their license current. At least two of these hours need to be in the topics of infection control and/or tobacco cessation. The majority of respondents $(62 \%)$ state that they choose to complete continuing education courses in both topics. See Figure 16.

Figure 16: Continuing Education Course Topics Completed $(n=424)$

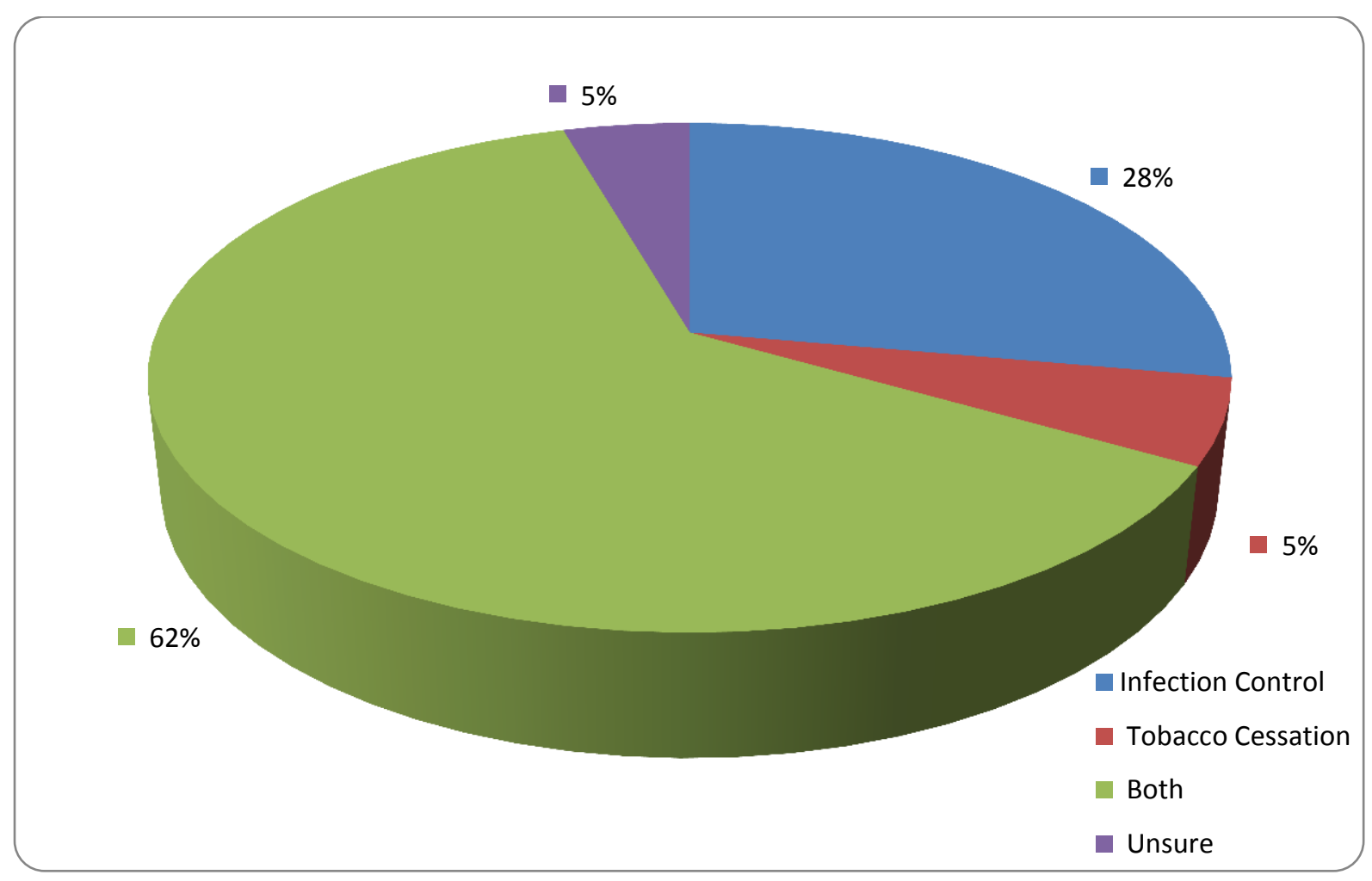


As health care providers, we are responsible for knowing the medical conditions of our patients. Many times patients fail to alert the dental hygienist of any changes in their health since their last appointment. It is imperative that patients complete new health history or update forms on a regular basis. The responding hygienist varied on how often their patients complete a new health history. A large number of hygienists chose the "Other" choice and further explained that their patients complete a new health history every 2, 3, or 5 years. See Figure 17.

Figure 17: Frequency of New Health Histories Completed by Patients $(n=421)$

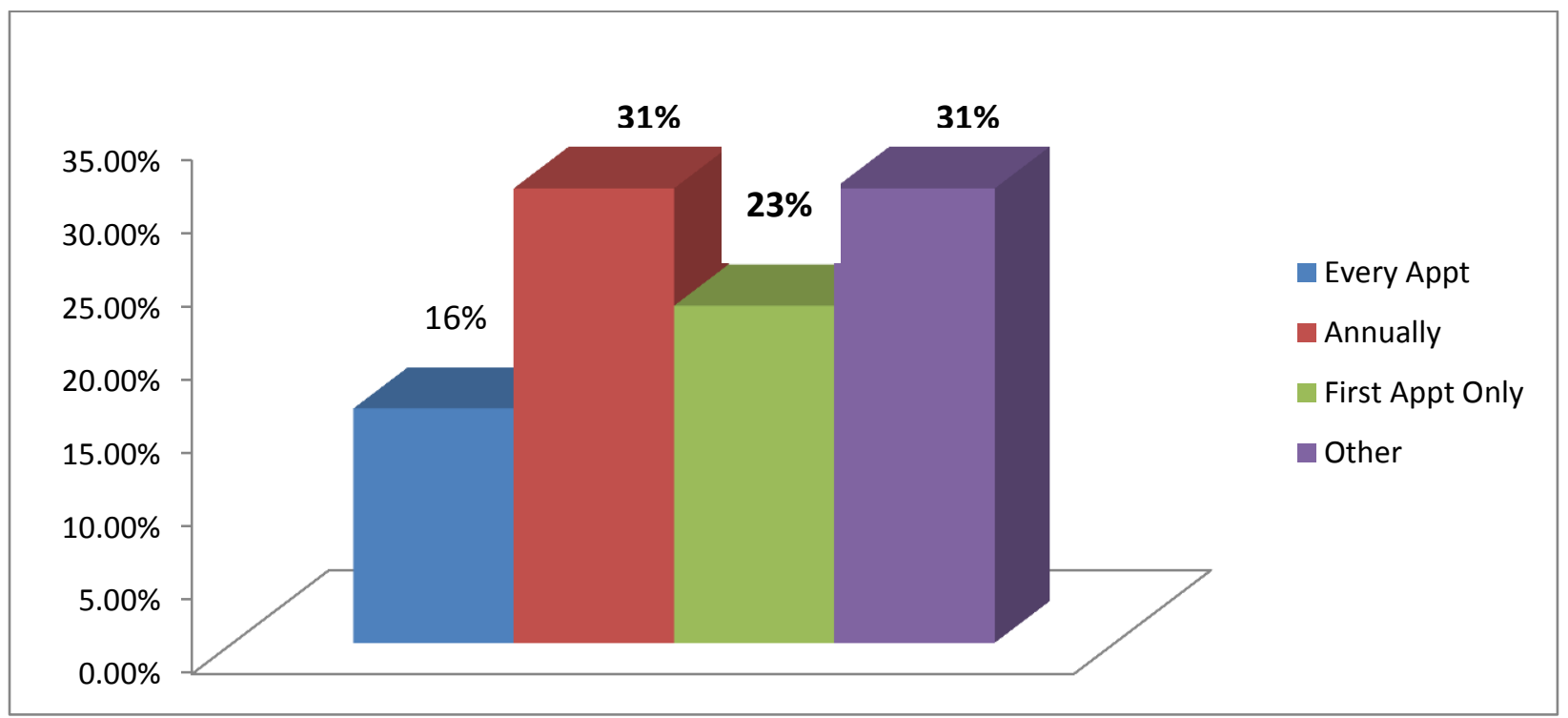


Since there is no standard health history form utilized by all offices, the information contained in these forms varies greatly from office to office. Respondents were asked if the following topics were included on the health histories used in their office: tobacco habits; alcohol consumption; history of human papilloma virus (HPV); and difficulty in swallowing. Respondents were asked to check all that apply. The use of tobacco was included on the majority of health histories used by the hygienists. See Figure 18.

Figure 18: Topics Included on Health Histories $(n=423)$

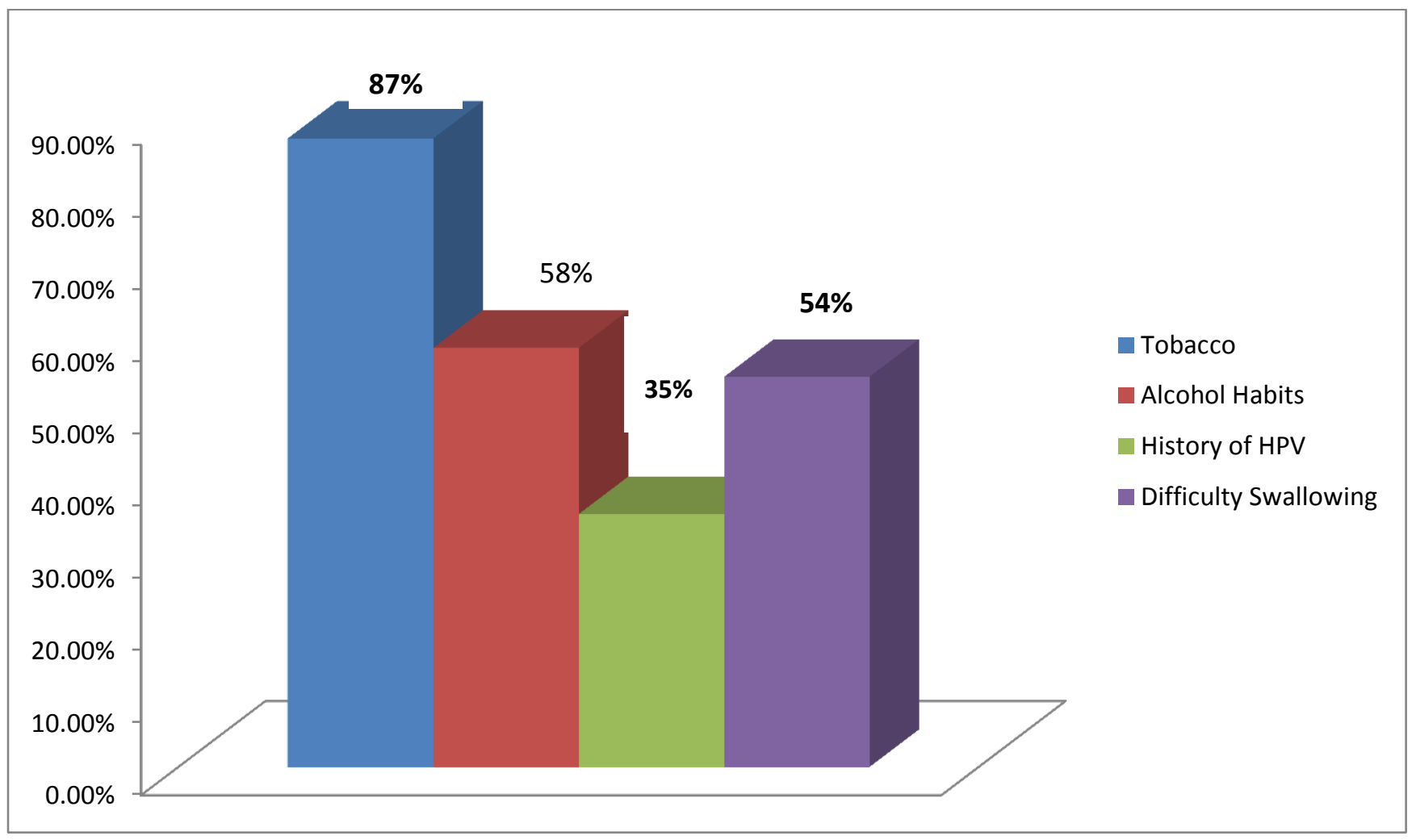


At the end of the survey, the hygienists were asked to rate their personal feelings on different aspects of oral cancer. A five-point scale was used where 1=strongly disagree; $2=$ disagree; $3=$ neutral; $4=$ agree; and 5=strongly agree. An "N/A" choice was also available for selection. For interpretation purposes, the responses were grouped together as follows: 1 and $2=$ disagree; $3=$ neutral; and 4 and 5=agree. See figures 19-24.

Figure 19: Confidence level in ability to detect oral cancer $(n=420)$

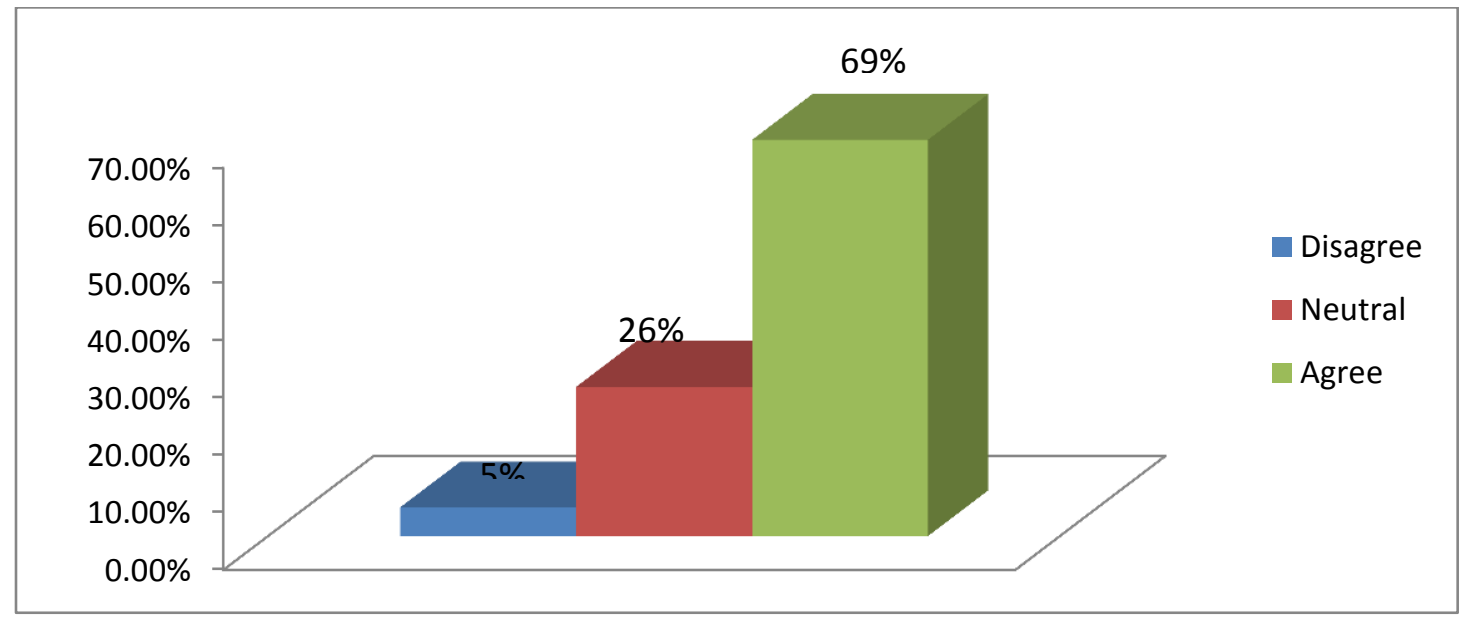

Figure 20: Confidence level in knowledge of oral cancer $(n=421)$

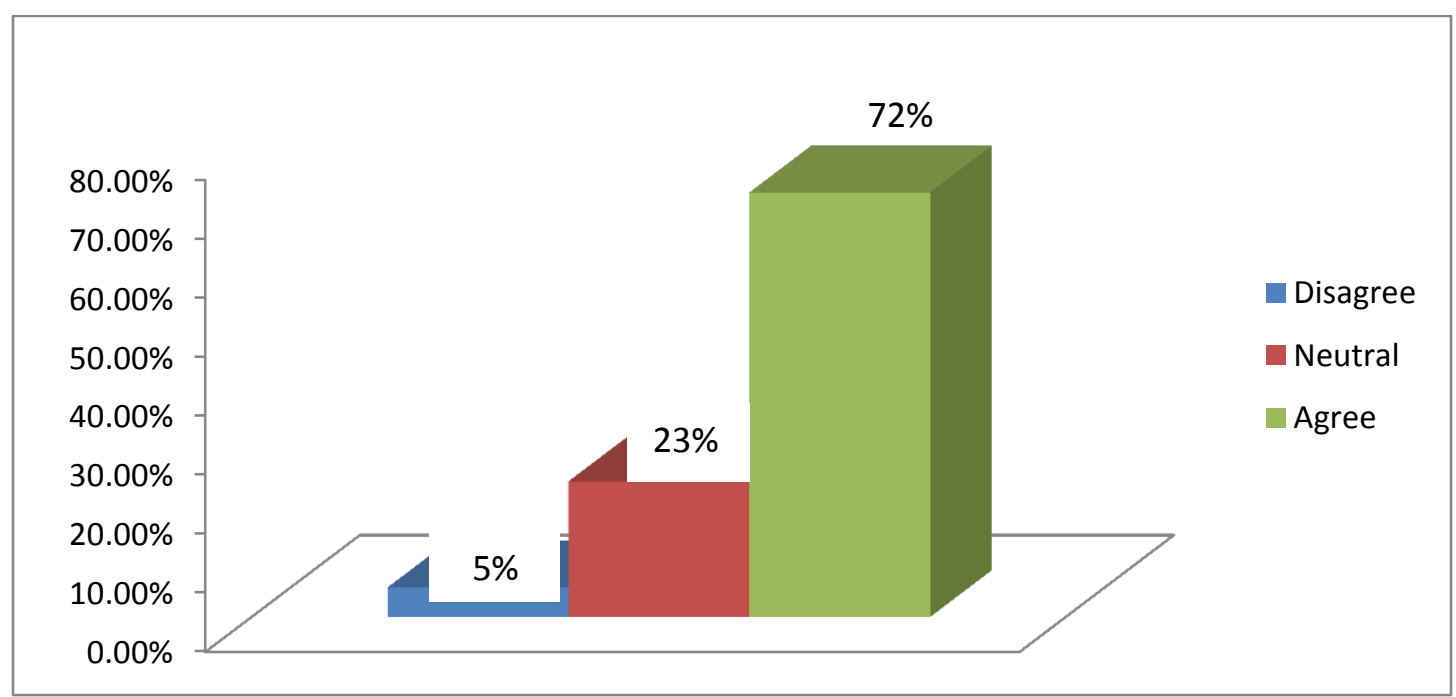


Figure 21: Confidence level in abiltity to discuss oral cancer $(n=421)$

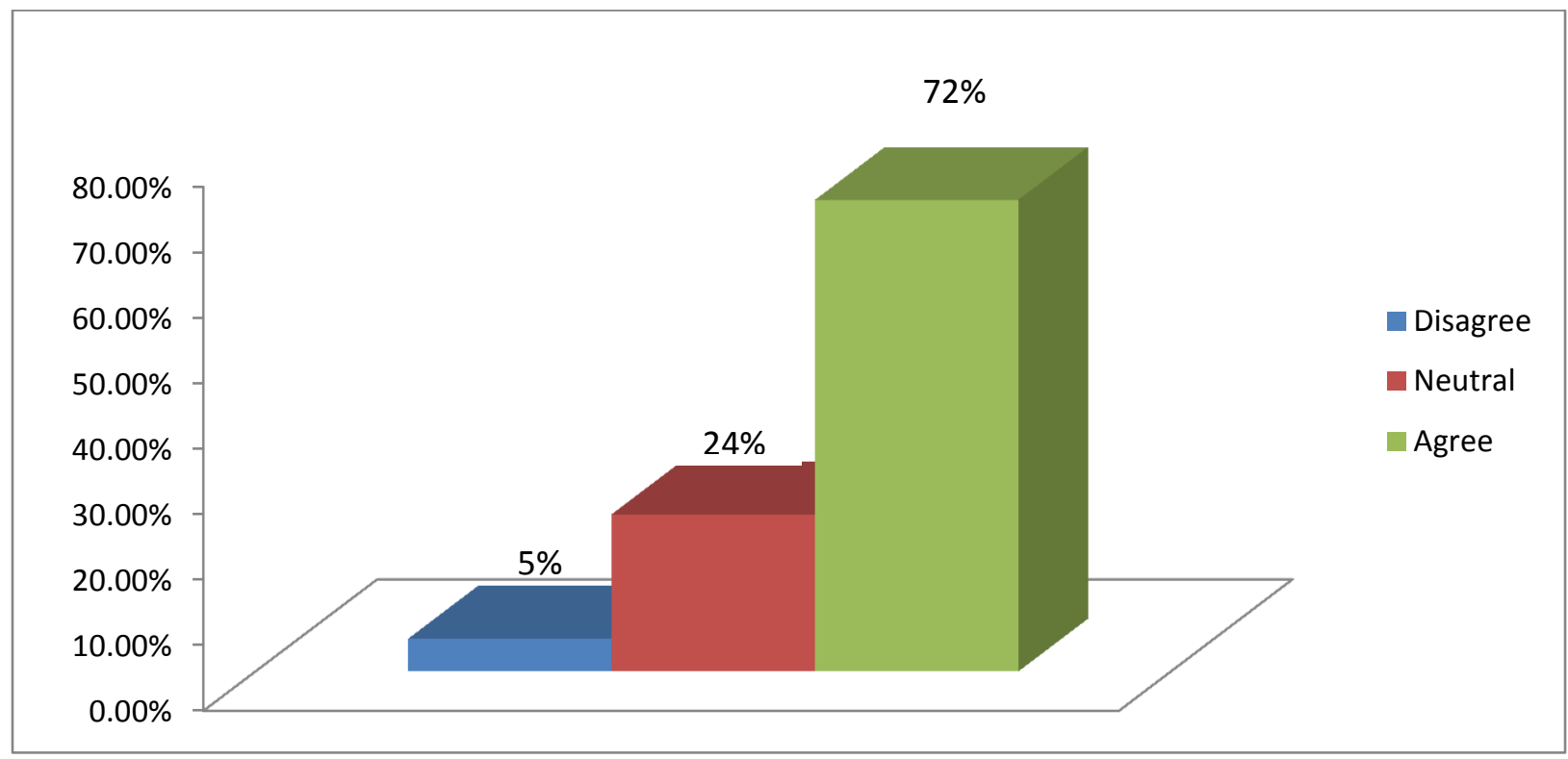

Figure 22: Adequate time allotted to complete oral cancer screening $(n=420)$

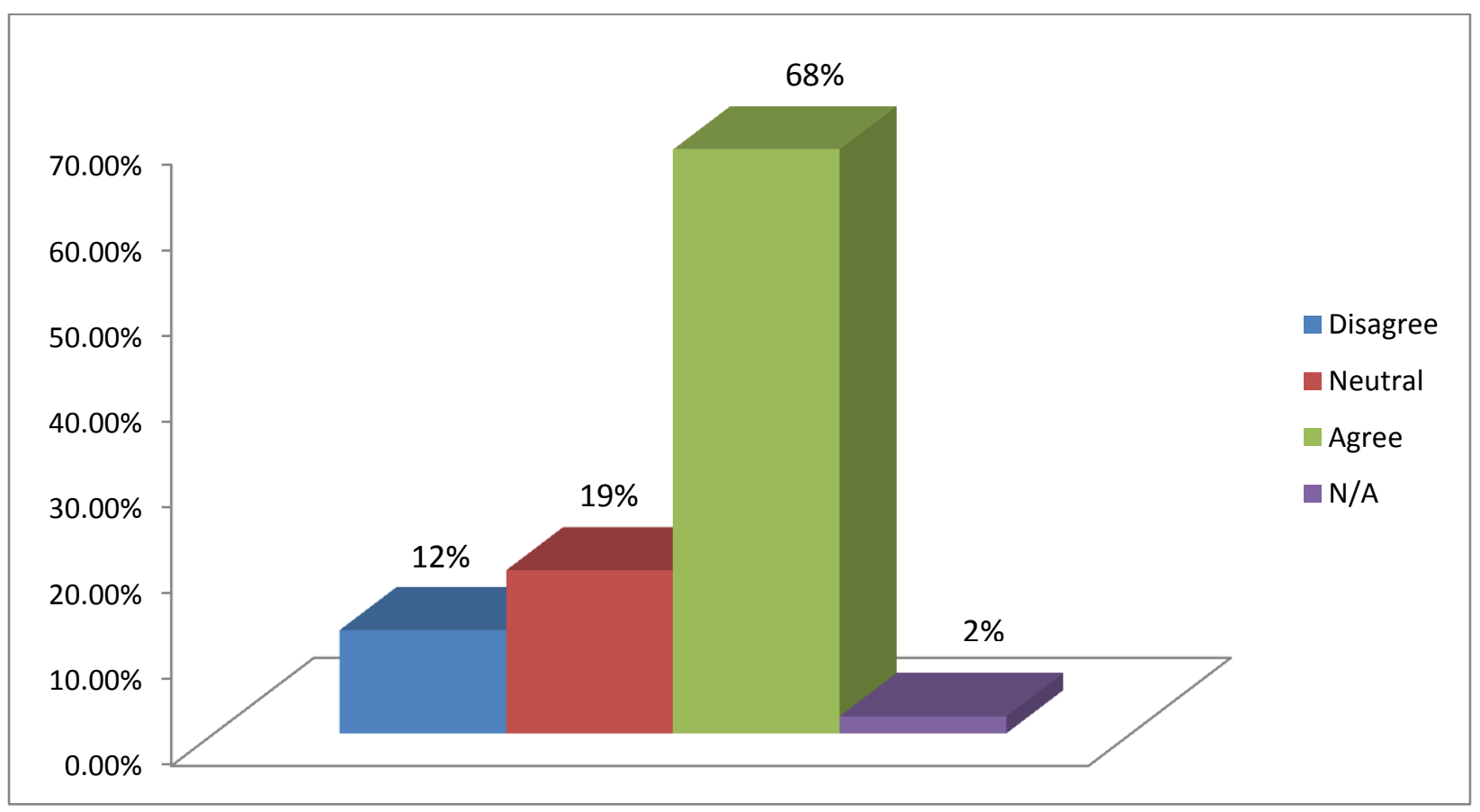


Figure 23: Hand-held fluorescent detection devices easy to use $(n=415)$

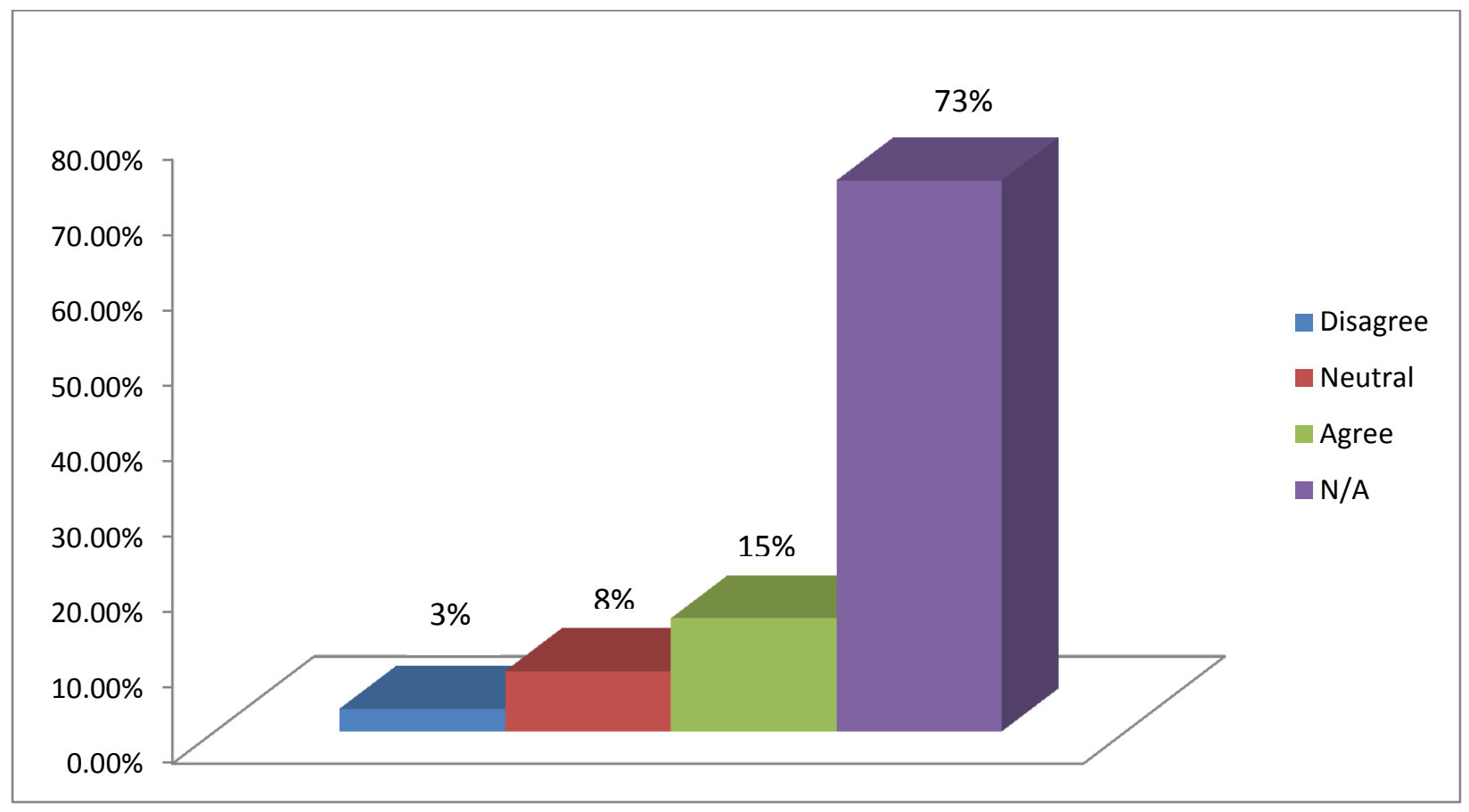

Figure 24: Confidence level in ability to discuss tobacco cessation $(n=421)$

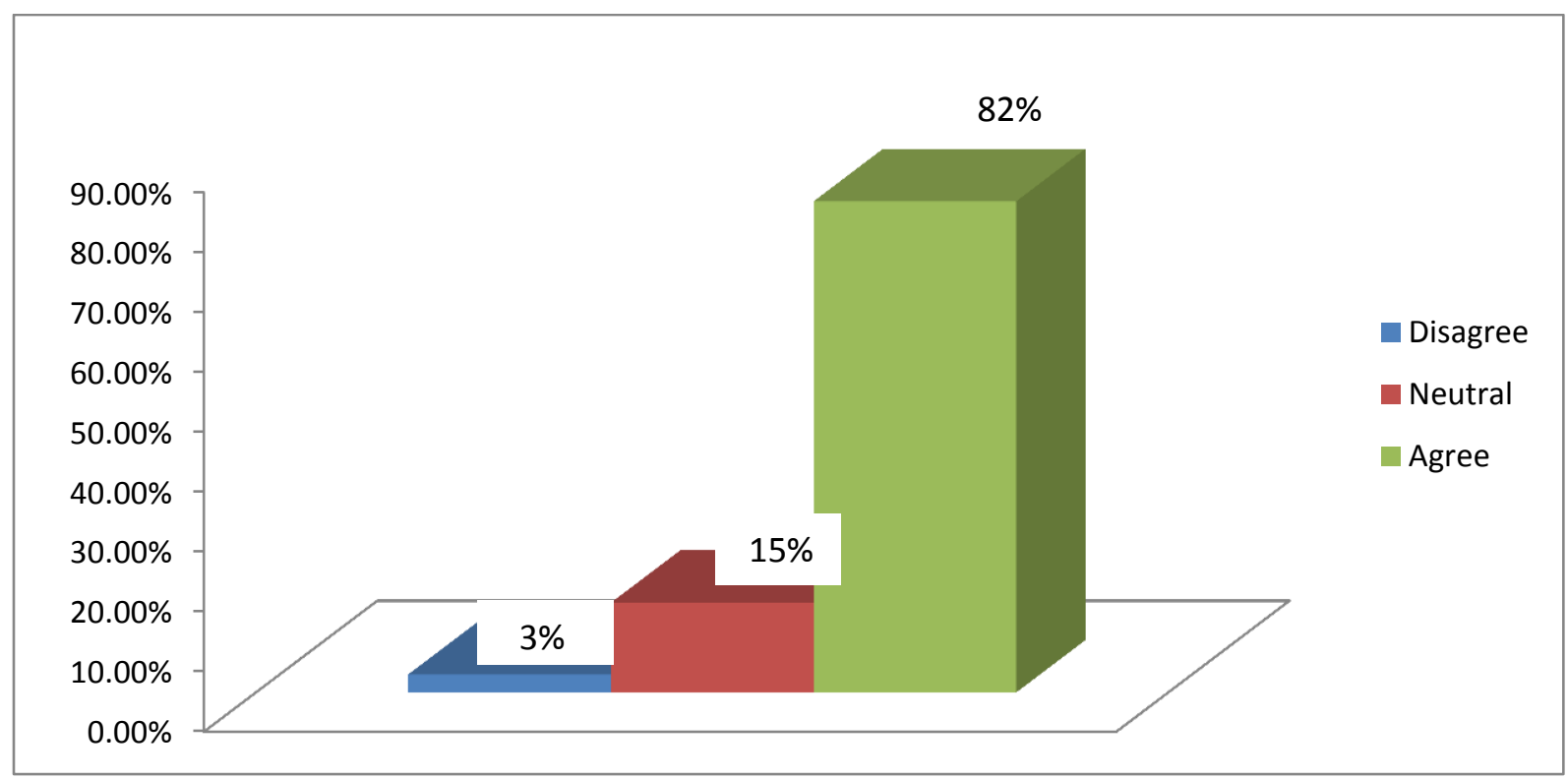




\section{DISCUSSION}

Oral cancer continues to be a deadly epidemic that could be diminished if adequate screening would take place in the dental office and at home. Dental hygienists need to assume the responsibility of not only screening their patients effectively, but also providing them with the tools and knowledge they need to screen themselves.

Dental hygienists have the choice to obtain an associate or bachelor's degree of dental hygiene to practice in the state of West Virginia. The responding dental hygienists were almost evenly split between the two degrees with the associates degree barely outnumbering the bachelor's degree (52\% and 46\%, respectively). West Virginia schools offer both the two-year associates degree and the four-year baccalaureate degrees. The majority had been practicing for more than twenty-one years $(39 \%)$. There was also a large response rate $(23 \%)$ from hygienists that had been practicing for less than five years. The large number of respondents from this age group may be the result of the respondents personally knowing the investigator. The responding dental hygienists represented forty-nine of West Virginia's fifty-five counties. More data would be needed to assess what counties in West Virginia currently do not employ a dentist or hygienist.

The majority of offices, $(96 \%)$, are performing oral cancer screenings; of these offices, $75 \%$ state that an oral cancer screening is completed by both the doctor and the hygienist. The majority of respondents $(95 \%)$ state that an oral cancer screening is performed at every recall appointment in hygiene. The respondents vary in the age that they begin performing oral cancer screenings. Most hygienists, $(32 \%)$, stated that they perform an oral cancer screening on all patients, regardless of age. The next age group that hygienists begin performing oral cancer 
screenings on is the $16-20$ years range (28\%). The introduction of oral cancer screenings at this age may be related to the legal age to purchase tobacco products, 18 years. Most hygienists, (73\%) claim that they inform patients when they are perfoming the oral cancer screening. The $27 \%$ of hygienists that do not notify their patients during the oral cancer screenings may be the result of a lack of confidence in evaluating what they are seeing or feeling. Hygienists may also feel that an adequate oral cancer screening is performed during the prophylaxis and does not require separate notification.

Patient education is a definite responsibilty of the dental hygienist. Patients develop a close bond with their hygienist because they generally spend more time with them than the dentist. The majority of responding hygienists, $(89 \%)$, claim to provide patients with tobacco cessation counseling and/or materials. However, the majority of hygienists, (54\%), do not instruct their patients on how to perform an adequate at-home oral cancer screening. All patients should be informed on what abnormalities within the mouth call for a closer evaluation. Tobacco users should absolutely be instructed on how to examine their own mouths for any suspicious lesions. Intra-oral cameras are a excellent adjunct to patient education. Intra-oral cameras visualize what patients are unable to see with the naked eye. Only $54 \%$ of the responding hygienists have access to an intra-oral camera in their office. The hygienists that do not have access to an intra-oral camera, should still make their patients aware of any abnormalities through the use of mirrors.

Only $16 \%$ of the responding hygienists currently work in an office that uses one of the hand-held fluorescence screening devices. Of this 16\%, 28 hygienists use the VELScope, 16 use the ViziLite, three use Identafi, two use Trimera, and 20 did not specify which system they were 
currently using. The reason for the low percentage of use may be attributed to the high cost to purchase these devices. The dentist also has to charge a significant fee when a patient chooses to have this type of screening. Insurance companies presently do not offer any type of reimbursement for this service. Some of the hand-held devices require a setting that is not conducive to the average dental office. A dark operatory is one necessity. Also, once a patient rinses with the specific solution the hygienist may have to wait a long period before the dentist is available to check any suspicious areas. Future data would be necessary to evaluate how long the wash remains active. Current research is inconclusive regarding accuracy and potential risks.

The oral brush biopsy was only utilized in $26 \%$ of the offices where the responding hygienists are employed. This seems like a significantly low number, however, $97 \%$ of the responding hygienisits state that their patients are referred to a specialist for an excisional biopsy of any suspicious lesion. Color, size, and duration of lesion were main factors in the referral rate $(89 \%, 88 \%$, and $86 \%$ respectively). Eighteen percent of respondents checked the "other" choice and provided these reasons for referral: appearance, location, and pain. Unfortunately, $74 \%$ of respondents claimed that their office annually only performs biopsies or refers patients for biopsy less than ten times. This number seems very low when compared to the annual rate of new oral cancer diagnoses. One possible reason for the low number of brush biopsy utilization is due to state laws. Currently, the West Virginia practice act for dental hygienists does not permit dental hygienists to perform brush biopsies.

Each office has implemented its own regimen of updating a patient's health history. Many offices require that patients complete a new health history annually (31\%). Thirty-one percent of responding hygienists also chose the "other" choice and provided that their patients 
complete a new health history every two, three, or five years. Patients may not understand that a slight change in their overall health can greatly affect their oral health. More frequent updates of these forms can help to reduce the chance of missing vital information. The majority of responding hygienists (87\%) state that the current health history used in their office addresses the patient's tobacco habits. Other areas addressed include alcohol consumption (58\%), history of HPV (35\%), and difficulty in swallowing (54\%). Due to the increase of oral cancers associated with HPV, medical histories used by dental offices need to address this topic more frequently. A standard health information form designed by the American Dental Association would ensure that all areas of importance are addressed.

When questioned about their overall feelings regarding oral cancer, most hygienists answered positively, but the alarming factor is that $96 \%$ of dental hygienists are conducting oral cancer screenings and there were no confidence levels above $72 \%$. Sixty-nine percent feel confident in their ability to detect oral cancer. Seventy-two percent feel confident in their knowledge of oral cancer. Seventy-two percent feel confident discussing oral cancer with their patients. The lower confidence levels calls for the need for more continuing education courses to be required on oral cancer. Sixty-eight percent feel that they are allotted adequate time to complete an oral cancer screening on each patient. Eighty-two percent feel confident in their ability to discuss tobacco cessation with their patients. In regards to the hand-held fluorescence screening devices, only $15 \%$ of respondents felt they were easy to use. The majority of respondents $(73 \%)$ chose the "N/A" option for this question due to not using these devices.

The results of this research illustrate a need for a mandated oral cancer screening to be implemented by all dentists and dental hygienists. Reimbursement for oral cancer screenings 
from insurance companies would also help to increase the frequency of these vital screenings. In order for the insurance companies to implement reimbursement, they need to be educated on how an increase in adequate oral cancer screenings will result in a decrease of late-stage diagnosis and resulting costs. 


\section{CONCLUSIONS}

The results of the study suggest:

- West Virginia dental offices are performing some form of oral cancer screening on patients, whether the patients are aware at the time of screening or not.

- Dental professionals are not fully utilizing available methods of screening for oral cancer, such as the hand-held fluorescence devices and brush biopsies.

- Technology driven (intra-oral cameras and hand-held fluorescence detection devices) patient education practices are limited

- Patient's health histories are not updated adequately.

- The majority of West Virginia dental hygienists feel confident in discussing oral cancer and related topics with their patients. 


\section{RECOMMENDATIONS}

Advancements in dental technology have greatly improved the way dental professionals are able to treat their patients. The hand-held fluorescence screening devices and the brush biopsy have the ability to increase the rate of diagnosis at an early stage. However, these adjuncts are not being utilized often enough. The following recommendations are made based on the results of this study:

- State dental board to mandate oral cancer screenings on all patients

- Universal oral cancer screening technique adopted by all practitioners

- Reimbursement from insurance companies for oral cancer screenings provided

- Standard health history form to be utilized and updated regularly by all dental offices

- Increased requirement of continuing education on oral cancer topics including technique for performing an exam and the recognition of oral cancer, types of oral cancer, and other related topics such as tobacco cessation

- A health history database, accessed by health care professionals in any field, that will combine all forms into one.

- The American Cancer Socity should re-evaluate the guidelines for oral cancer screenings. An increase in the diagnosis of younger individuals calls for a change in screening ages.

Patients will only benefit from the advancement of oral cancer screening techniques. By regulating the frequency and thoroughness of oral cancer screenings, the patient can feel 
confident that they are receiving the best preventive care possible. Early diagnosis will also help contribute to a decrease in overall medical bills, pain, and suffering. 


\section{FUTURE RECOMMENDATIONS FOR STUDY}

- A study that would focus on the sensitivity and specificity of the hand-held fluorescence screening devices.

- A study that would survey dentists on their oral cancer screening techniques.

- A study that would survey other states regarding their oral cancer screening techniques.

- A study that would survey what oral cancer screening techniques are being taught in dental hygiene programs.

- A study that would evaluate what is available to dental offices in different areas of West Virginia. 


\section{REFERENCES}

1. Sugden, Keverly. 2010. Life or death: improving oral cancer screenings. $R D H$ Magazine, 30(2), 80-82.

2. Oral cancer facts. Available: www.oralcancerfoundation.orgg Accessed 19 May 2010.

3. Neville, Brad W., Day, Terry A., Oral cancer and precancerous lesions. 2002. A Cancer Journal for Clinicians, 52(4), 195-213.

4. Ibsen, Olga A. C. 2008. The missing link. Dimensions of Dental Hygiene, 6(11), 22-26.

5. CDC oral cancer background papers. Available: www.oralcancerfoundation.org Accessed 19 May 2010.

6. A detailed description of brush cytology, and the oral brush biopsy. Available: www.oralcancerfoundation.org Accessed 14 July 2010.

7. Screening the non-high risk oral cancer patient. Available: www.oralcancerfoundation.org Accessed 19 July 2010.

8. Mignogna, Michele D., Fedele, Stefano. 2005. Oral cancer screening: 5 minutes to save a life. The Lancet, 365(9475), 1905-1906.

9. Warnakulasuriya, K.A.A.S., Harris, C.K., Scarrott, D.M., Watt, R., Gelbier, S., Peters, T.J., Johnson, N.W. 1999. An alarming lack of public awareness towards oral cancer. British Dental Journal, 187(6), 319-322. 
10. Sapp, Phillip J., Eversole, Lewis R., Wysocki, George P. 2004. Contemporary Oral and Maxillofacial Pathology.

11. Blot, William J., McLaughlin, Joseph K., Winn, Deborah M., Austin, Donald F., Greenberg, Raymond S., Preston-Martin, Susan, Bernstein, Leslie, Schoenberg, Janet B., Stemhagen, Annette, Fraumeni, Joseph F. 1988. Smoking and drinking in relation to oral and pharyngeal cancer. Cancer Research, 48, 3282-3287.

12. Rothman, Kenneth, Keller, Andrew. 1972. The effect of joint exposure to alcohol and tobacco on risk of cancer of the mouth and pharynx. Journal of Chronic Diseases, 25, 711-716.

13. Winn, Deborah. 1995. Diet and nutrition in the etiology of oral cancer. American Journal of Clinical Nutrition, 61(supplement), 437-445.

14. Mashberg, Arthur, Boffetta, Paolo, Winkelman, Regina, Garfinkel, Lawrence. 1992. Tobacco smoking, alcohol drinking, and cancer of the oral cavity and oropharynx among U.S. veterans. International Journal of Cancer, 52(4), 530-533.

15. Fakhry, Carole, Gillison, Maura L. 2006. Clinical implications of human papillomavirus in head and neck cancers. Journal of Clinical Oncology, 24(17), 2606-2609.

16. D’Souza, Gypsayamber, Kreimer, Aimee R., Viscidi, Raphael, Pawlita, Michael, Fakhry, Carole, Koch, Wayne M., Westra, William H., Gillison, Maura L. 2007. Case-control study of human papillomavirus and oropharyngeal cancer. New England Journal of Medicine, 356, 1944-1956. 
17. Shiboski, Caroline H., Schmidt, Brian L., Jordan, Richard C.K. 2005. Tongue and tonsil carcinoma. The American Cancer Society: Cancer, 103(9), 1843-1849.

18. Haddad, Robert I. 2007. Human papillomavirus infection and oropharyngeal cancer. Available: www.medscape.org Accessed 19 July 2010.

19. Rathore, Ajit Singh, Chhina, Shivjot, Ahuja, Puneet. 2011. Newer screening aids for detection of precancerous and cancerous lesions of oral cavity. Journal of Indian Dental Association, 5(3), 373-374.

20. Screening aides: oral cancer screening devices. Available: www.dentalproductsreport.com Accessed 21 June 2010. 
Appendix A

IRB Exemption 


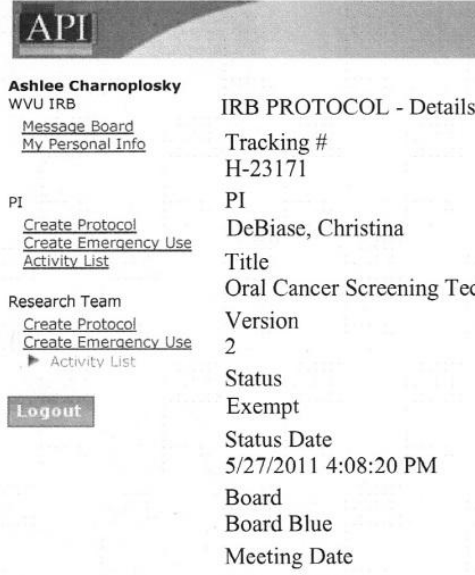

API

Ashlee Charnoplosky
WVU IRB

Message Board

COL - Details

Tracking \#

H-23171

PI

PI

Create Protocol $\quad$ DeBiase, Christina

$\frac{\text { Create Emergency Use }}{\text { Activity List }}$ Title

Research Team Oral Cancc

Create Protocol Version

Create Emercency Use 2

Status

Logout Exempt

Status Date

5/27/2011 4:08:20 PM

Board

Board Blue

Meeting Date

Annrovenl Noto

Select an Action: Copy

https://ecomp.wvu.edu/Protocols/TaskDetails.aspx?ActivityId=13808898\&application=Br... 7/28/2011 
Appendix B

Dental Hygiene Survey 
Please circle your answer.

1. What dental hygiene degree do you possess?
Bachelors
Associate
Other

2. How many years have you been practicing?
$<5$
6-10
$11-15$
$16-20$
$21+$

3. In what county do you practice?

4. Does your office perform oral cancer screenings?

Yes No

(If answer is no, skip to question 9.)

5. Who usually performs the oral cancer screenings?
$\mathrm{RDH}$
DDS
Both
Other

6. Do you tell your patient when you are doing an oral cancer screening?

Yes No

7. How often is an oral cancer screening performed in your office?

Initial Appointment Every Recall Only when problem is present Never

8. At what age do you begin performing oral cancer screenings on patients?
$0-5$
6-10
11-15
$16-20$
$21+$

9. Do you instruct patients to perform oral cancer screenings at home?

Yes No

10. Do you provide tobacco cessation counseling and/or materials?

Yes No

11. Does your office perform brush biopsies of oral tissue?

Yes No

12. Does your office refer patients to a specialist for biopsies?

Yes No

If yes, what prompts you to refer? (Check all that apply)

Color__ Size____ Duration of Presence___ Other 
13. On average, how many biopsies or referrals for biopsy does your office perform each year?

$$
0-10 \quad 11-20 \quad 21-30 \quad \text { over } 30
$$

14. Does your office use a fluorescence tool to aid in the detection of oral cancer?

Yes No

If yes, which tool does your office use?

15. Does your office use intra-oral cameras for patient education?

Yes No

16. WV State law requires hygienists to complete at least 3 hours of continuing education courses in infection control and/or tobacco cessation topics. Which do you typically choose to complete?

Infection Control Tobacco Cessation Bnsure

17. How often do your patients complete a new medical history?

Every Appointment Annually $\quad$ First Appointment Only

Other

18. Which of the following are included on the medical history? (Check all that apply)

Tobacco Habits

Alcohol Consumption

History of Human Papilloma Virus (HPV)

Difficulty in Swallowing

Other

Using the following scale, please circle the number that best indicates your personal feelings.

1...Strongly Disagree $\quad 2 . .$. Disagree $\quad 3 . .$. Neutral $\quad 4$...Agree $\quad 5 . .$. Strongly Agree

19. I am confident in my ability to detect oral cancer.

$\begin{array}{llllll}1 & 2 & 3 & 4 & 5 & \mathrm{NA}\end{array}$

20. I am confident in my knowledge of oral cancer.

$\begin{array}{llllll}1 & 2 & 3 & 4 & 5 & \mathrm{NA}\end{array}$

21. I am confident discussing oral cancer with my patients. $\quad \begin{array}{llllllll} & 2 & 3 & 4 & 5 & \mathrm{NA}\end{array}$

22. I have adequate time to complete an oral cancer screening. $\quad \begin{array}{llllllll} & 1 & 2 & 3 & 4 & 5 & \mathrm{NA}\end{array}$

23. I find the hand-held fluorescence illumination tools easy to use. $\quad \begin{array}{lllllll}1 & 2 & 3 & 4 & 5 & N A\end{array}$

24. I am confident in my ability to discuss tobacco cessation

with my patients.

$\begin{array}{llllll}1 & 2 & 3 & 4 & 5 & \mathrm{NA}\end{array}$ 
I visually inspect the following areas as part of my oral cancer screening. (Check all that apply)

\section{Extraoral Exam}

Overall Skin Appearance

Lips

Swallowing

TMJ Function

Intraoral Exam

Vestibular Mucosa

Buccal Mucosa

Hard Palate

Soft Palate

Uvula

Palatine Tonsils

Tonsillar Pillars

\section{Lymph Nodes}

Pre-Auricular

Post-Auricular

Submandibular

Submental

Cervical

\section{Tongue}

Dorsum

Lateral

Ventral

Floor of Mouth

I use palpation as part of my oral cancer screening on the following areas. (Check all that apply)

\section{Extraoral Exam}

Overall Skin Appearance

Lips

Swallowing

Thyroid Gland

TMJ Function

\section{Intraoral Exam}

Vestibular Mucosa

Buccal Mucosa

Hard Palate

Soft Palate

Uvula

Palatine Tonsils

Tonsillar Pillars
Lymph Nodes

Pre-Auricular

Post-Auricular

Submandibular

Submental

Cervical

Tongue

Dorsum

Lateral

Ventral

Floor of Mouth 
I use a hand-held fluorescence illumination tool on the following areas during my oral cancer screening. (Check all that apply) (If you do not use a fluorescence illumination tool, please skip this question.)

\section{Extraoral Exam}

Overall Skin Appearance
Lips

Tongue

Dorsum
Lateral
Ventral
Floor of Mouth

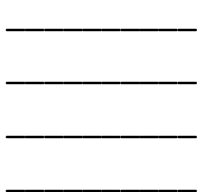

\section{Intraoral Exam}

Vestibular Mucosa
Buccal Mucosa
Hard Palate
Soft Palate
Uvula
Palatine Tonsils
Tonsillar Pillars

Buccal Mucosa

Hard Palate

Soft Palate

Tonsillar Pillars 
Appendix C

Cover Letter First Mailing 
April 1, 2011

Dear Fellow Dental Hygienist,

My name is Ashlee Charnoplosky and I am currently pursuing a Master of Science degree in Dental Hygiene from West Virginia University. To fulfill requirements for my master's thesis, I am surveying all dental hygienists in West Virginia. My research project is being conducted by Dr. Christina DeBiase MA, EdD, Principal Investigator, Ashlee Charnoplosky, BSDH, Dr. Susan Morgan, DDS, and Cathryn Frere MSEd .

The purpose of my research is to examine techniques currently being used by dental hygienists to screen patients for oral cancer. Each year over 8,000 Americans will die from oral cancer. As dental hygienists, we are professionally responsible for performing head and neck screenings on all patients in our care. A variety of questions will be addressed ranging from current screening techniques used to referral rates to specialists for biopsies of suspicious tissues.

Your participation in this research study is completely voluntary. Every measure will be taken to keep your answers as confidential as possible. Refusal to participate will have no negative effect on you or my standing as a student at West Virginia University. The survey will take no more than 10 minutes to complete. You are not required to answer all questions; however, the completeness of your responses will greatly benefit the outcome of the survey. Please return your completed survey in the postage paid envelope provided on or before May 1, 2011. West Virginia University's Institutional Review Board (IRB) has acknowledgement of this study on file.

Sincerely,

Christina DeBiase, EdD

Associate Dean for Academic \& Postdoctoral Affairs

WVU School of Dentistry
Ashlee Charnoplosky, BSDH

Graduate Student

Division of Dental Hygiene

WVU School of Dentistry
Cathryn Frere, MSEd

Associate Professor

Division of Dental Hygiene

WVU School of Dentistry
Susan Morgan, DDS

Clinical Assistant Professor

Department of Periodontics

WVU School of Dentistry 
Appendix D

Cover Letter Second Mailing 
Dear Fellow Dental Hygienist,

My name is Ashlee Charnoplosky and I am currently pursuing a Master of Science degree in Dental Hygiene from West Virginia University. To fulfill requirements for my master's thesis, I am surveying all dental hygienists in West Virginia. My research project is being conducted by Dr. Christina DeBiase MA, EdD, Principal Investigator, Ashlee Charnoplosky, BSDH, Dr. Susan Morgan, DDS, and Cathryn Frere MSEd .

The purpose of my research is to examine techniques currently being used by dental hygienists to screen patients for oral cancer. Each year over 8,000 Americans will die from oral cancer. As dental hygienists, we are professionally responsible for performing head and neck screenings on all patients in our care. A variety of questions will be addressed ranging from current screening techniques used to referral rates to specialists for biopsies of suspicious tissues.

Your participation in this research study is completely voluntary. Every measure will be taken to keep your answers as confidential as possible. Refusal to participate will have no negative effect on you or my standing as a student at West Virginia University. The survey will take no more than 10 minutes to complete. You are not required to answer all questions; however, the completeness of your responses will greatly benefit the outcome of the survey. Please return your completed survey in the postage paid envelope provided on or before June 1, 2011. West Virginia University's Institutional Review Board (IRB) has acknowledgement of this study on file.

Sincerely,

Christina DeBiase, EdD

Associate Dean for Academic \& Postdoctoral Affairs

WVU School of Dentistry
Ashlee Charnoplosky, BSDH

Graduate Student

Division of Dental Hygiene

WVU School of Dentistry
Cathryn Frere, MSEd

Associate Professor

Division of Dental Hygiene

WVU School of Dentistry
Susan Morgan, DDS

Clinical Assistant Professor

Department of Periodontics

WVU School of Dentistry 


\title{
VITA
}

\section{Ashlee Brooke Charnoplosky}

\author{
2011 \\ 1302 Carlisle Ave \\ Morgantown, WV 26505 \\ 304-685-0917 \\ ashlee.charnoplosky@gmail.com
}

\section{EDUCATION}

Master of Science, Dental Hygiene, West Virginia University, August 2011

Thesis: "Oral Cancer Screening Techniques Performed by West Virginia Dental Hygienists"

Advisor: Dr. Christina DeBiase

3.85 GPA upon graduation

Bachelor of Science, Dental Hygiene, West Virginia University, May 2007

\section{LICENSURE}

West Virginia Board of Dental Examiners, License \#2790, March 2008 to present South Regional Board Examination, March 2007 National Board of Dental Hygiene Examination, March 2007 


\section{CERTIFICATIONS}

General Supervision Permit, July 2010, Certificate \#2010-GS-0518

Monitoring Nitrous Oxide, April 2010, Certificate \#2010-DHNC-0991

\section{EMPLOYMENT}

Clinical Hygiene:

Dental Hygienist, Frum and Cid Dental Arts, May 2008 - Present

Dental Hygienist, Dental Center of Taylor County, March 2008 - August 2008

\section{Teaching Experience:}

Graduate Assistant, West Virginia University, School of Dentistry, Department of Endodontics, Part-time Jan 2010 - May 2011

Assisted $3^{\text {rd }}$ and $4^{\text {th }}$ year dental students providing endodontic care to patients. Instructed dental students on using sensors to expose digital radiographs. Managed infection control compliance of students.

Dental Hygiene Clinical Assistant, Course Requirement for Graduate Program, August 2008 -May 2009

Provided clinical instruction/evaluation for $3^{\text {rd }}$ and $4^{\text {th }}$ year dental hygiene students.

\section{HONORS/DISTINCTIONS}

Sigma Phi Alpha, May 2007 (Current president of WVU chapter)

$2^{\text {nd }}$ Place Research Poster, National Dental Hygiene Conference, New Orleans, LA 2007 
$1^{\text {st }}$ Place Research Poster, WVU, Division of Dental Hygiene, Feb 2007

\section{ACADEMIC SERVICE/SCHOLARLY ACTIVITY}

DENT 701 - Instructed $1^{\text {st }}$ year dental students in patient positioning, illumination, dental and periodontal charting, and gingival/oral evaluations

\section{COMMUNITY SERVICE}

Monongalia General Hospital Health Fair - Provided oral instruction/evaluation, Morgantown Mall, Feb 2010, 2011

SADHA Welcome Back Picnic, August 2010

Children's Dental Health Fair, Mountaineer Mall, Spring 2006, 2007

Greenbrier County 4H Camp - Provided oral hygiene instruction, Summer 2006

\section{RESEARCH}

MASTERS RESEARCH, WVU, August 2011

Thesis: Oral Cancer Screening Techniques Performed by WV Dental Hygienists

A survey of all practicing WV dental hygienists to evaluate oral cancer screening protocols in their respective offices.

UNDERGRADUATE RESEARCH, WVU, Feb 2007

Title: "Country Roads to Oral Care, The WV RHEP Program" 
A retrospective study of the Rural Health Externship Preceptor Program (RHEP Program) on services provided and impact on employment of dental hygienists in rural areas of WV.

\section{RECENT CONTINUING EDUCATION COURSES ATTENDED}

CPR/BLS, American Heart Association, March 2011, 2 CE

Invisalign Clear Essentials I, Dec 2010, 8 CE

OSHA Annual Training, Nov 2010, 2 CE

Hazard Communication, Nov 2010, 0.5 CE

Infection Control, Nov 2010, 1.5 CE

CT Guided Surgery: From Plan to Prosthesis, June 20102 CE

Reducing Cancellations and Failures, April 2010, 1.5 CE

Emergency Medicine in Dentistry, April 2010, 6.5 CE

Tobacco Cessation Provider Training, April 2010, 3 CE 